\title{
ASSOCIATED OBSTETRIC AND PERINATAL DETERMINANTS OF VANISHING TWIN PREGNANCIES \\ Ph.D. Thesis
}

\author{
Virág Katalin Márton, M.D. \\ University of Szeged \\ Albert Szent-Györgyi Health Centre \\ Faculty of Medicine \\ Department of Obstetrics and Gynecology
}

Supervisor:

Attila Keresztúri, M.D., Ph.D., Med. Habil.

University of Szeged

Albert Szent-Györgyi Health Centre

Faculty of Medicine

Department of Obstetrics and Gynecology

Director of Doctoral School of Clinical Medicine:

Lajos Kemény, M.D., D.Sc.

Director of Reproductive Health Programme:

György Bártfai, M.D., D.Sc.

\author{
University of Szeged \\ Albert Szent-Györgyi Health Centre \\ Faculty of Medicine \\ Department of Obstetrics and Gynecology
}

Szeged, 2020 


\section{LIST OF PUBLICATIONS}

I. Márton V, Zádori J, Kozinszky Z, Keresztúri A. Prevalences and pregnancy outcome of vanishing twin pregnancies achieved by in vitro fertilization versus natural conception. Fertil Steril. 2016 Nov.;106(6):1399-1406. IF 2016: 4.447

II. Márton V, Németh G., Keresztúri A., Iker vagy sem? A vanishing twin fenomén. Magyar Nőorvosok Lapja. 2018.81 (6). pp. 330-337

III. Márton V, Zádori J, Keresztúri A, Kozinszky Z. Associated perinatal determinants of vanishing twin pregnancies achieved by in vitro fertilization vs. spontaneous conception. Arch Gynecol Obstet. 2020 Feb.;301(2):491-498. IF(2018): 2.199

\section{OTHER PUBLICATIONS}

I. Keresztúri A, Kozinszky Z, Daru J, Pásztor N, Sikovanyecz J, Zádori J, Márton V, Koloszár S, Szöllösi J, Németh G. Pregnancy Rate after Controlled Ovarian Hyperstimulation and Intrauterine Insemination for the Treatment of Endometriosis following Surgery. Biomed Res Int.2015; 2015:282301. IF 2015: 2.134

II. Kozinszky, Z., Pásztor, N., Márton, V., Sikovanyecz, J., Keresztúri, A., \& Németh, G. (2017). Transabdominal amnioinfusion in the correction of oligohydramnios following twin-to-singleton reduction - A report of two cases. Case Reports in Perinatal Medicine, $6(1)$.

III. Molnár, B. G., Kormányos, Z., Márton, V., Anðelic, L., \& Góli, A. (2011). Parallel hysteroscopic and laparoscopic myomectomy in infertile patients. Gynecological Surgery, 9(2), 151-154. 


\section{TABLE OF CONTENTS}

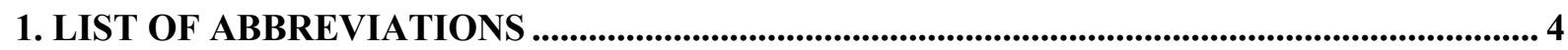

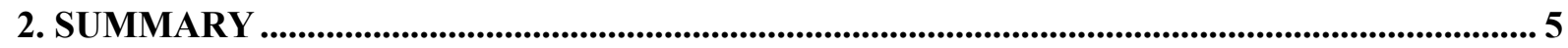

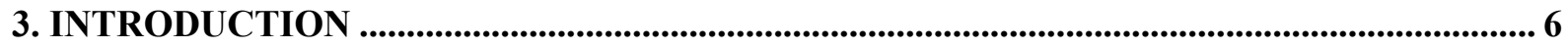

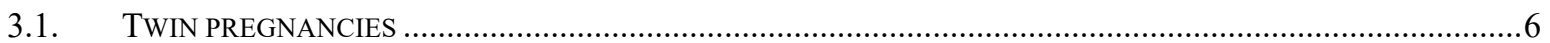

3.2. SPONTANEOUS LOSS IN TWIN PREGNANCIES (AFTER ART AND AFTER NATURAL CONCEPTION) ...............8

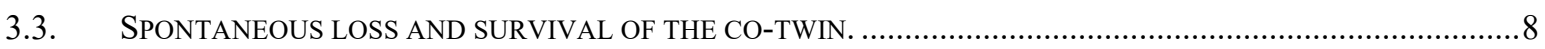

DIAGNOSIS, INCIDENCE AND PATHOMECHANISM OF VANISHING TWIN SYNDROME ................................................

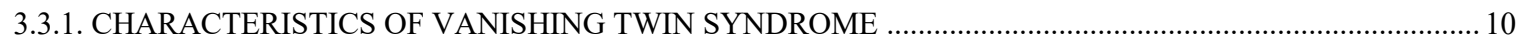

3.3.2. VTS INFLUENCE ON NIPT (NON-INVASIVE PRENATAL TESTING) ......................................................... 12

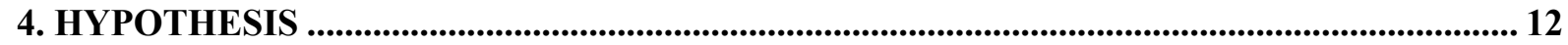

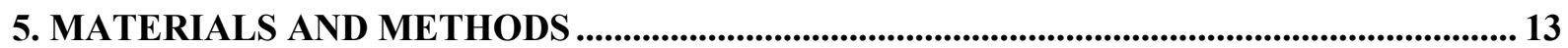

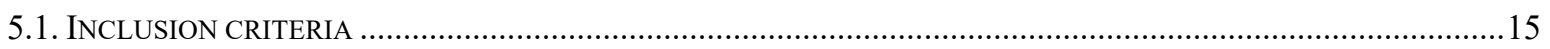

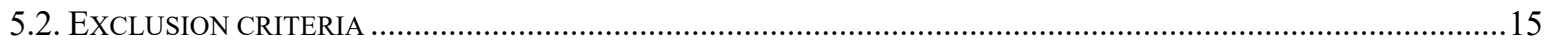

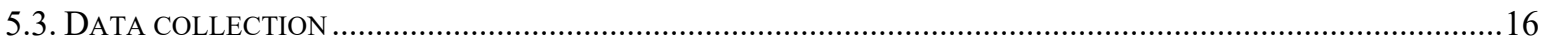

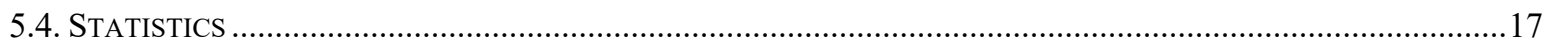

6. SUMMARY OF RESULTS ............................................................................................................ 18

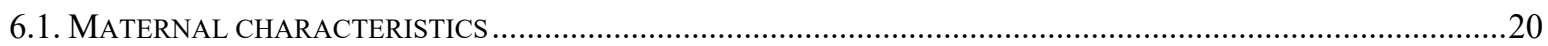

6.2. PREGNANCY CHARACTERISTICS AND INTRAPARTUM COMPLICATIONS ....................................................23

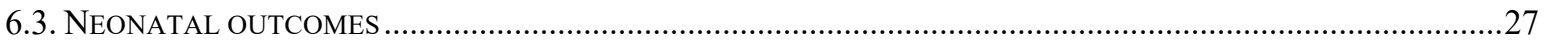

6.4. INDEPENDENT RISK FACTORS ASSOCIATED WITH THE VANISHING TWIN PHENOMENON...............................30

7. DISCUSSION OF SPECIFIC RESULTS AND COMPARISON WITH OTHER STUDIES . 32

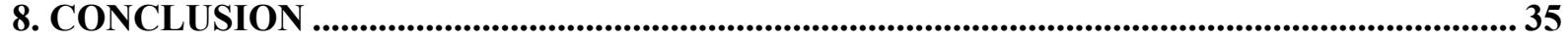

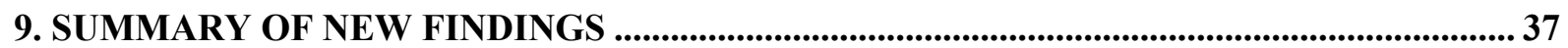

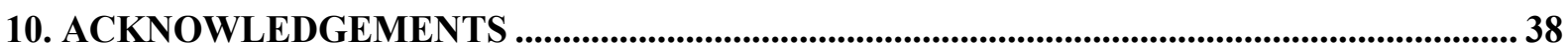

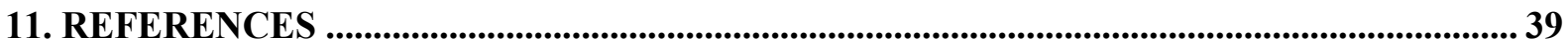




\section{LIST OF ABBREVIATIONS}

\begin{tabular}{|c|c|}
\hline AOR & adjusted odds ratio \\
\hline AR & assisted reproduction \\
\hline ART & assisted reproductive technique \\
\hline ß-hCG & beta human chorionic gonadotrophin \\
\hline BMI & body mass index $(\mathrm{kg} / \mathrm{m} 2)$ \\
\hline BW & birth weight \\
\hline $\mathrm{CI}$ & Cornfield's 95\% confidence interval \\
\hline CRL & crown-rump length \\
\hline $\mathrm{DC}$ & dichorionic \\
\hline DET & double embryo transfer \\
\hline DNA & deoxyribonucleic acid \\
\hline DZ & dizygotic \\
\hline EIM & European IVF-monitoring Consortium \\
\hline GDM & gestational diabetes mellitus \\
\hline GS & gestational sac \\
\hline IUGR & intrauterine growth restriction \\
\hline IUI & intrauterine insemination \\
\hline IVF & in-vitro fertilization \\
\hline IVF/ICSI & in-vitro fertilization/intracytoplasmic sperm injection \\
\hline LBW & low birth weight \\
\hline $\mathrm{MC}$ & monochorionic \\
\hline MZ & monozygotic \\
\hline $\mathrm{NC}$ & natural conception \\
\hline NICU & neonatal intensive care unit \\
\hline NIPT & non-invasive prenatal testing \\
\hline OR & odds ratio \\
\hline $\mathrm{PE}$ & preeclampsia \\
\hline SGA & small for gestational age \\
\hline SNP & single-nucleotide polymorphism \\
\hline T1DM & type 1 diabetes mellitus \\
\hline US & ultrasound \\
\hline VLBW & very low birth weight \\
\hline VT & vanishing twin \\
\hline VTS & vanishing twin syndrome \\
\hline
\end{tabular}




\section{SUMMARY}

A retrospective cohort study was carried out to reveal the characteristics and the perinatal outcome of vanishing twin pregnancies after spontaneous conception and after assisted reproductive techniques (ART).

Vanishing twin (VT) syndrome, defined as the disappearance of one of two embryos with the survival of the co-twin during the first trimester, has been known for more than four decades. Due to the high and ever growing number of assisted reproductive treatments, the incidence of twin pregnancies and thus of vanishing twin syndrome is high. Recent studies have only examined vanishing twins after ART, but we hypothesized that there is a difference in perinatal outcomes between VT pregnancies, depending on the mode of conception, possibly reflecting the potential differences between underlying pathomechanisms.

Our study consisted of two parts. We initiated the first study to compare obstetric and neonatal outcomes between the survivors of VT pregnancies and matched originally singleton control pregnancies, and a second study to evaluate whether VT pregnancies after spontaneous conception have a more adverse perinatal outcome than those conceived after assisted reproductive techniques.

The study involved 316 VT pregnancies: 81 after in-vitro fertilization/intracytoplasmic sperm injection (IVF/ICSI) and 235 after spontaneous conception. Their data were derived from databases in a 22-year study period at the Department of Obstetrics and Gynecology, University of Szeged, Szeged, Hungary.

Our results proved that the frequency of VT pregnancies was significantly higher after natural conception than after ART. A comparison of VT pregnancies demonstrated a higher rate in pregestational and gestational diabetes mellitus (GDM) in IVF/ICSI cases than in spontaneously conceived VT pregnancies. Significant differences in the prevalences of pregnancies and intrapartum complications, and adverse neonatal outcomes were observed in vanishing twins born after IVF/ICSI as compared with those born after implantation without medical assistance, suggesting that adverse perinatal outcome in IVF/ICSI VT pregnancies may be more related to ART or infertility and underlying chronic diseases. Previous induced abortion and second-trimester fetal loss indicated an increased risk of VT pregnancies, while 
GDM and prematurity of previous pregnancies predicted VT and growth retardation, particularly in the spontaneously conceived VT group.

Diabetes is classically defined as being associated with a higher miscarriage rate. We observed a higher recurrence rate of gestational diabetes and increased incidence of pregestational and gestational diabetes mostly in IVF/ICSI VT pregnancies, suggesting that diabetes may share a pathomechanism with VT. After identifying the causes that lead to vanishing twin syndrome, GDM, chronic maternal diseases, advanced maternal age and placentation anomalies all represented independent risk factors for VT following IVF/ICSI.

It can be established that the VT phenomenon was a major prognosticator of intrauterine growth restriction for the remaining fetus in VT pregnancies after ART. In conclusion, according to our results, VT is quite frequent. VT pregnancies had a lower prevalence and a worse perinatal outcome following IVF/ICSI as compared with those of their spontaneously conceived counterparts.

\section{INTRODUCTION}

\subsection{Twin pregnancies}

Twins and twinnings as a unique result of human reproduction have been followed with interest through the centuries. Twinning is a complex and multifactorial phenomenon, and elements of the twinning process during the early human embryonic development are not completely understood.

Twins have always captivated curious investigators and have been the subject of myths, but they have also provided an opportunity to understand early human embryonic development.

From the aspect of development, there are two types of twins, dizygotic (DZ) and monozygotic (MZ) twins [1], each with a very different etiology. DZ twinning occurs when two separate oocytes are fertilized by two sperm in the same menstruation cycle. MZ twins arise when an embryo splits soon after fertilization. MZ twins carry essentially identical genetic instructions in contrast with DZ twins, who have the same genetic relationship as ordinary 
siblings. The mechanism of DZ development is known: two mature follicles release two oocytes for fertilization. Despite our familiarity with the mechanisms which lead to separation of the cells into two embryos immediately after fertilization, the process for MZ twins is still not fully understood.

Twins are not rare; however, the spontaneous rate of twinning seems to remain rather constant over time, about $1-1.5 \%$ in Europe [2]. The constant frequency is characteristic of spontaneous MZ pregnancies, but the rate of spontaneous DZ pregnancies due to altered environmental factors seems to be slightly elevated [3]. The major factors influencing twinning are maternal age, parity, environmental factors and genetic inheritance, but these factors basically determine the DZ twinning rate, and not the MZ twinning rate [3]. The invariable frequency of $\mathrm{MZ}$ pregnancies, independently of maternal characteristics and geographic distribution over time, suggests that MZ twins are predominantly determined by genetic mechanisms [4].

Growing infertility, delayed childbearing and the strong demand for assisted reproductive techniques have led to an increased rate of DZ twin pregnancies and have been cited as the main iatrogenic cause in the past two decades [5]. The latest annual report published by the European IVF-monitoring Consortium (EIM) reported 776556 ART treatment cycles in 2014, which showed a continuing expansion in number of treatments and resulted in a total of 170163 ART infants. Moreover, according to the EIM report, one in 50 European children are born after ART treatments and the proportion of twin deliveries is $23.3 \%$ [6]. The frequency of twinning is usually expressed as the incidence out of 1000 maternities. Within Europe, twinning rates vary between 11 and 20 per 1000 maternities, with the variation being the result of DZ twinning rates. MZ twinning rates remain constant at about 4 per 1000 maternities [7]. The twin ratio refers to twin live births and does not correlate with the twin conception rate. Indeed, twin conception does not necessarily result in twin birth; spontaneous loss could affect one or both of the fetuses [8], [9]. 


\subsection{Spontaneous loss in twin pregnancies (after ART and after natural conception)}

The overall incidence of spontaneous loss rate in the first trimester is about 10-20\%, irrespective of the mode of conception or the number of embryos [10]. Maternal, fetal and iatrogenic factors are responsible for a spontaneous reduction in twin pregnancies. The rate of spontaneous loss in twin pregnancies varies widely, between 33 and $62 \%$, and is influenced by maternal age, mode of conception and gestational age [11]-[13]. The risk of embryonic loss has been reported lower with the appearance of embryonic structure and cardiac activity [14]. The true incidence of spontaneous abortion is unknown because many abortions occur before pregnancy is clinically recognized, making it more difficult to determine, especially with naturally conceived pregnancies. In contrast, pregnancy after ART is diagnosed earlier by maternal blood B-hCG (beta human choriogonadotrophin) level or by transvaginal ultrasound because of an increased maternal motivation and demand to follow the long-awaited pregnancy.

Earlier studies established that the incidence of spontaneous abortion is slightly higher after the IVF (in-vitro fertilization) procedure than after natural conception, and the main reason is higher maternal age [15], [16]. In a comparison of singleton pregnancies with twin pregnancies after IVF/ICSI (in-vitro fertilization/intracytoplasmic sperm injection) treatment, the incidence of spontaneous abortion was significantly lower in twin pregnancies. However, it increased with maternal age in both groups [10]. The spontaneous loss rate among twin pregnancies is determined by chorionicity, with a higher embryonic loss rate found in monochorionic (MC) twins compared with dichorionic (DC) twins [17], [18].

\subsection{Spontaneous loss and survival of the co-twin. Diagnosis, incidence and pathomechanism of vanishing twin syndrome}

Spontaneous loss in twin gestation with the survival of the "remaining" embryo was suggested more than 70 years ago and has been recognized since the advent of sonography [8], but the data on the true reduction rate are limited. Improvement of the ultrasound technique with better visualization of the early stages of pregnancy has more clearly demonstrated that spontaneous selective reduction is rather a frequent event in multiple pregnancies [11].

The definition of the vanishing twin phenomenon as an early gestational loss of one twin and survival of the co-twin originated from Levi and has not changed since the first description 
in 1976 [19]. More recently, the term "vanishing twin" implies some uncertainty, described as resorption of one of two gestational sacs if both of them were visible before (Figure 1), or, by strict criteria, identification of two different gestational sacs with two visible embryos with a heart rate before one of them vanishes in the first trimester.

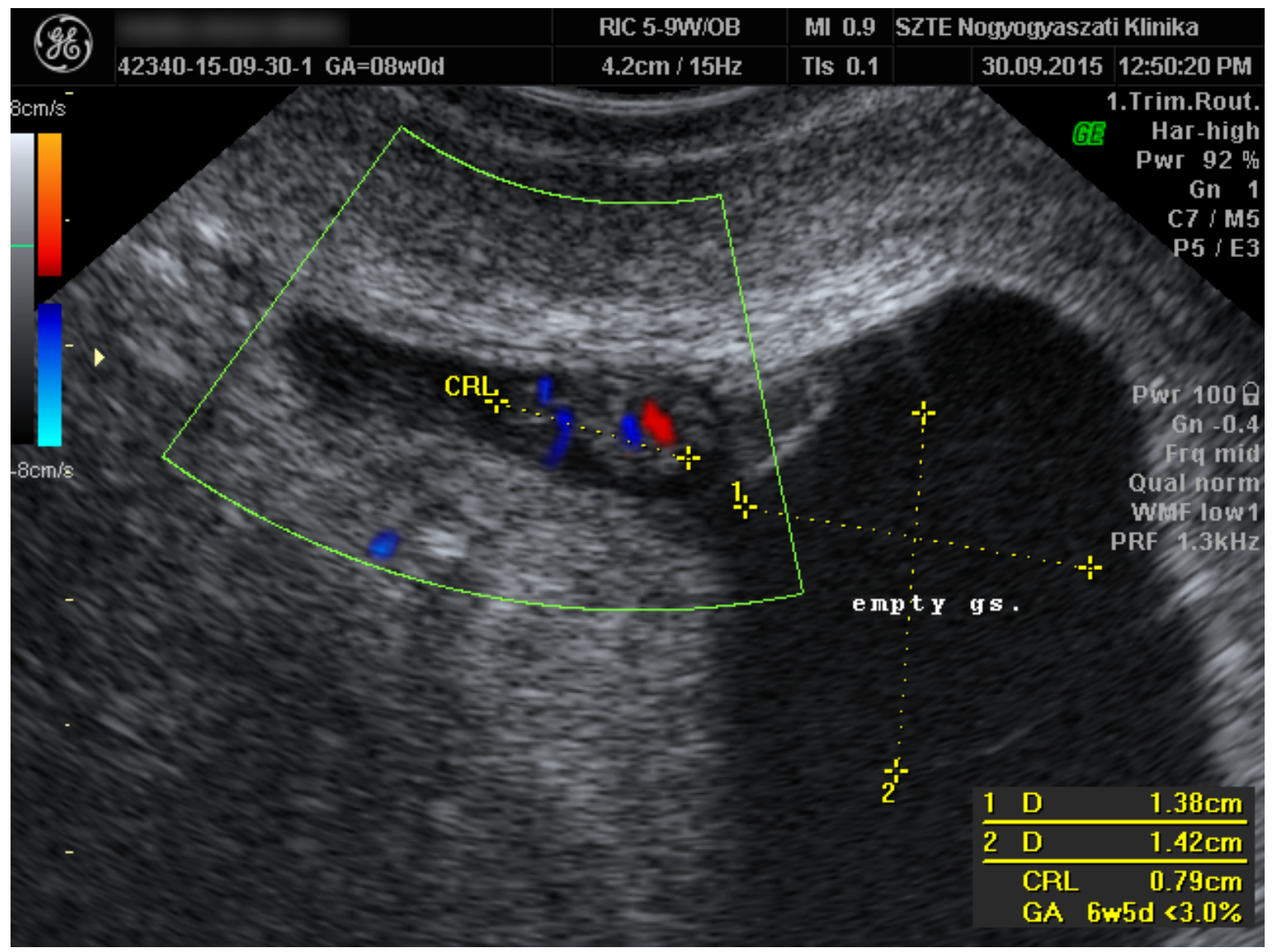

Figure 1. Vanishing twin pregnancy (gestational sac (GS) 1: live embryo; GS2: empty sac) (author's image)

The etiology of the VT phenomenon remains vague; however, placental degeneration [20] and chromosomal abnormality in the vanishing embryo [21] have been confirmed pathologically. Other possible causes, including inappropriate implantation, placental 
"crowding," intrauterine bleeding and chronic maternal diseases, have previously been suggested [9], [22]-[25].

The incidence of VT pregnancies varied between 10 and 39\% in pregnancies resulting from IVF/ICSI [11], [26]-[29].

ART increases the potential for twin conception rates and, hence, the incidence of VT pregnancies because double embryo transfer (DET) is still the routine and the most widely accepted method in most countries [30]. Transfer of one or two intermediate-quality embryos has been observed as the ART-bound prognosticator for vanishing twin [31].

VTS (vanishing twin syndrome) is not unusual; however, despite its importance to anxious parents and to the obstetrician, the exact prevalence of VT after spontaneous conception has remained unidentified [8], [12], [25].

A higher frequency of vanishing can be observed in triplet or multiple pregnancies. In one report, the rate of VTS was 36\% in twins and 53\% in triplets [11]. The vanished embryo is also a risk factor for adverse perinatal outcomes, and a similar unfavorable effect can even be seen in multiple pregnancies.

The pathomechanism of the VT phenomenon can be explained by insufficient uterine capacity for the development of two placentae or the lack of optimality of the current site on the decidualized endometrium for implantation and placentation [8], [25]. Moreover, the selection of a higher quality of embryo even with double embryo transfer can improve IVF/ICSI success [31], whereas the embryo quality following natural oocyte recruitment is enigmatic in spontaneous twin conceptions. Consequently, this may imply that the VT phenomenon has different pathomechanisms and prevalences in assisted vs. non-assisted conceptions [32].

\subsubsection{Characteristics of vanishing twin syndrome}

Identifying VTS with the advanced ultrasound (US) technique and equipment appears simple. In spite of the simplicity of the first ultrasound scan, if the vanishing occurs before the $6^{\text {th }}$ week of pregnancy, it can be a challenge to recognize and differentiate the multiple gestational sacs and the VT (Figure 2). It has been noted that spontaneous pregnancy loss mainly occurs between 8 and 9 weeks of gestation [12]. The most frequent clinical sign of 
embryonic loss is light vaginal bleeding, or "spotting", which has been observed in $15-25 \%$ of cases [33]. The presence of spotting appears with the vanishing process.

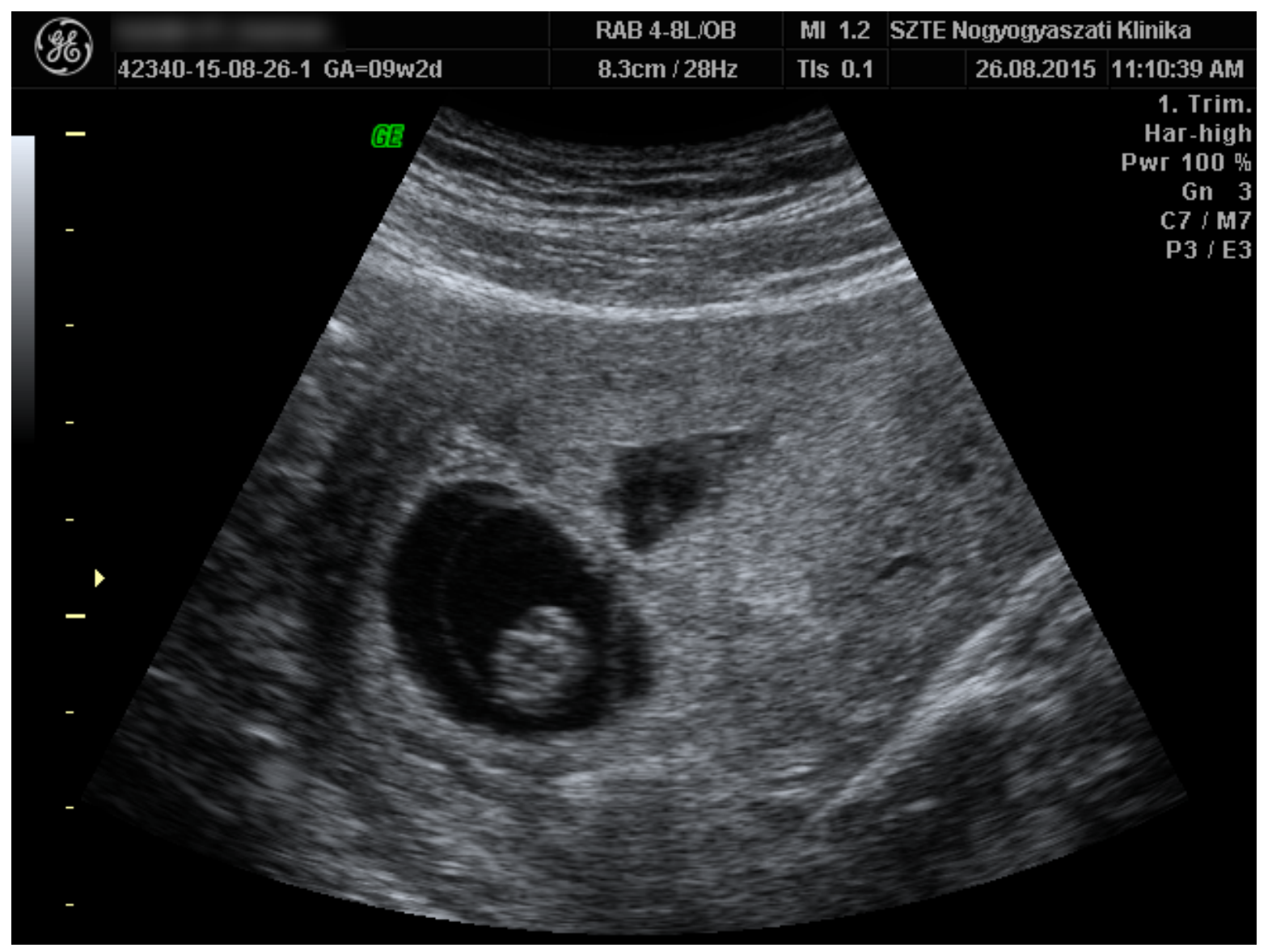

Figure 2. Identification of VTS with the first routine ultrasound pregnancy scan (author's image)

In VT pregnancies achieved with the IVF/ICSI technique, the disappearing embryo has a detrimental effect on the surviving co-twin, leading to intrauterine growth disturbances [10], [11], [26]-[29], [34], [35]. The VT phenomenon is also associated with an array of pregnancy complications (GDM, pregestational diabetes and hypertensive disorders) and neonatal sequelae (cerebral palsy) [28], [35]. 


\subsubsection{VTS influence on NIPT (non-invasive prenatal testing)}

The ability to detect VT is clinically important because VTS is a potential confounder of non-invasive prenatal testing (NIPT) results. The presence of biochemical markers and residual cell-free deoxyribonucleic acid (DNA) which are released from the residual trophoblast and embryonic tissues of the VT have a significant influence on the risk assessment of chromosomal abnormalities in the viable embryo [36], [37].

Unnoticed DZ vanishing twin can lead to false positive NIPT, bias the results and generate incorrect aneuploidity in the co-twin due to undetected residual cell-free DNA. Chromosomal abnormalities, mostly aneuploidity, are common in vanishing twins, and the available single-nucleotide polymorphism (SNP)-based NIPT method could reduce false positive screening results [38]-[40].

Singleton pregnancies complicated by VTS represent a special entity between singleton and twin pregnancies. Controversially, some studies have reported that the obstetric outcome of survivors of VT pregnancies after the IVF/ICSI technique is in between those of singletons and twins [10], [11], [20], [29], [41], whereas other authors have demonstrated that it is more comparable to those of singletons [42].

Most of the recent studies only demonstrate results among singleton survivors of VTS after IVF/ICSI. Earlier studies have not been analyzed for adverse obstetric or perinatal outcomes in VT pregnancies after spontaneous conception or differences in outcomes between VT survivors after spontaneous conception or after ART.

\section{HYPOTHESIS}

We hypothesized that there is a difference in perinatal outcomes between VT pregnancies following artificial conception and those following natural conception, possibly reflecting the potential differences between underlying pathomechanisms. 


\section{The aims of the present study were as follows:}

- To determine the incidence of VT pregnancies following spontaneous conception and after assisted reproductive techniques.

- To find the average gestational length at the time of vanishing.

- To determine whether we should consider VTS as a risk for various pregnancy complications or adverse perinatal outcome.

- To evaluate whether VT pregnancies after assisted reproductive techniques have a more adverse perinatal outcome than those after natural conception.

- To examine whether the impact of the VT phenomenon is the sole contributor to the adverse perinatal outcome in IVF/ICSI VT pregnancies.

- To demonstrate the effect of the IVF/ICSI technique on the VT phenomenon.

- To collect potential risk factors for VT pregnancies by mode of conception.

\section{MATERIALS AND METHODS}

This thesis involves two retrospective studies for VT pregnancies.

In an attempt to prove the hypothesis, we initiated (1) the first study to compare obstetric and neonatal outcomes between the survivors of VT pregnancies and matched originally singleton control pregnancies and (2) the second study to evaluate whether vanishing twin pregnancies after spontaneous conception have a more adverse perinatal outcome than those conceived after assisted reproductive techniques.

The first retrospective case-control study included data on VT pregnancies after IVF/ICSI and after spontaneous conception and their matched singleton control pregnancies detected between 1 January 1994 and 30 November 2014 at the Department of Obstetrics and Gynecology, University of Szeged (Figure 3). The first study included 65237 singleton deliveries, 1563 twins and 306 VT pregnancies. As regards the type of conceptions, $78 \mathrm{VT}$ cases resulting from IVF/IVF-ICSI and 228 VT cases were identified from spontaneously conceived twin pregnancies. 


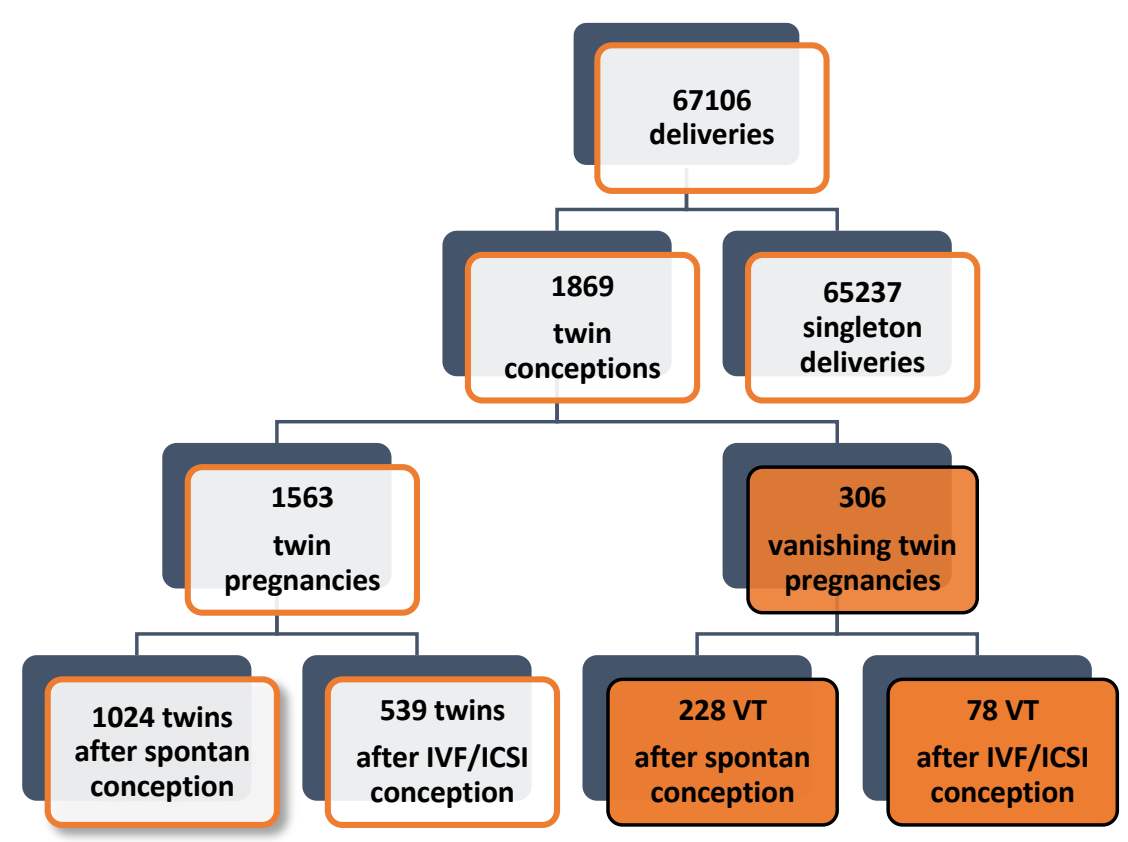

Figure 3. Flow chart of the included VT pregnancies in Paper 1

The second retrospective cohort study processed data on VT pregnancies, and perinatal and neonatal outcomes for these deliveries from an extended period with two more years after IVF/ICSI and after spontaneous conception (between January 1994 and January 2016) in the same single center. The vast majority of the assisted reproductive treatments were performed at the Center for Assisted Reproduction, Kaáli Institute, Szeged (Figure 4). The second study population consisted of 67827 singleton deliveries, 1941 twins and 316 VT pregnancies. 81 VT cases resulting from IVF/IVF-ICSI, and 235 VT cases were identified from spontaneously conceived twin pregnancies. 


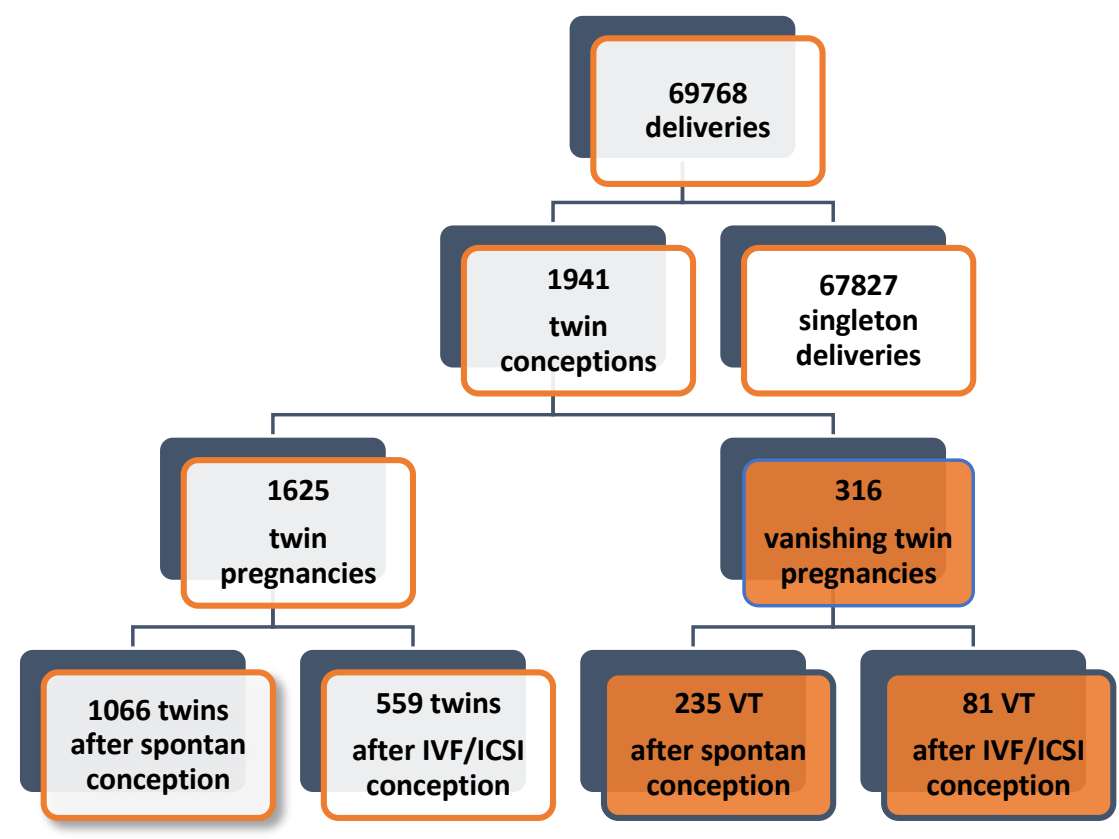

Figure 4. Flow chart of included VT pregnancies in Paper 2

Based on Protocol Nos. 14/2013 and 5/2015, the research project was approved by the Ethics Committee at the University of Szeged in accordance with the Code of Ethics of the Declaration of Helsinki for scientific research involving humans.

\subsection{Inclusion criteria}

In the study design, we used the classification for vanishing twin based on Landy's diagnosis. Vanishing twin was diagnosed in cases where two viable embryos with spontaneous reduction of one embryo or a single viable embryo and an additional gestational sac with or without a nonviable embryo were demonstrated before 14 weeks of gestation [21].

\subsection{Exclusion criteria}

All cases of single fetal loss identified after 14 gestational weeks or pregnancies after ovulation induction or intrauterine insemination (IUI) were excluded from the analyses. MC twins or singleton pregnancies after artificial fetal reduction were also excluded from both of the studies. We excluded VT pregnancies after ovulation induction with Clostilbegyt (clomiphene-citrate), insemination or gonadotrophin stimulation without ART because stimulation has an indirect effect on VT rate. It has been previously suggested that the 
spontaneous reduction rate is lower after ovulation induction because of more equal GS resulting in ovulation from a cohort of near equal sized follicles [11], [14].

\subsection{Data collection}

VT cases were identified by a manual systematic search of the entire sonography database, which was managed between the $5^{\text {th }}$ and $14^{\text {th }}$ gestational weeks during the study periods at our outpatient clinic at the Department of Obstetrics and Gynecology, University of Szeged. The data on maternal characteristics, VT pregnancies, neonatal outcomes and matched singleton control pregnancies were collected from obstetric and neonatal records. In the first study for each VT case, three controls were matched according to the following criteria: singleton pregnancies started as singleton gestations achieved by natural conception or IVF/ICSI, which were as similar as possible in maternal age, previous gravidity and parity and pre-pregnancy body mass index (BMI), and delivered after VT pregnancies in chronological order.

Demographic data, maternal characteristics, and obstetric and neonatal outcomes were retrieved from obstetric and neonatal databases and were exported to Microsoft Excel (Microsoft Corp., Redmond, WA, USA). Gestational age was established by the day of embryo transfer for the IVF/ICSI group and by sonographic measurement of the embryo in the first trimester for the spontaneous conception group. Intrauterine growth restriction (IUGR) was diagnosed when the growth curve had declined significantly below the $10^{\text {th }}$ percentile, resulting in a small fetus for pathological reasons. We defined birth weight as $<2500$ grams for low birth weight (LBW) and $<1500$ grams for very low birth weight (VLBW). Prematurity was defined as delivery at $<37$ weeks of gestation, and very premature birth was classified as birth at $<32$ weeks. The pre-pregnancy BMI registered at the initial visit during prenatal care was calculated as body weight $(\mathrm{kg})$ per height $\left(\mathrm{m}^{2}\right)$. Chronic maternal diseases (e.g. essential hypertension, cardiac, autoimmune and endocrine diseases, pre-existing diabetes, and thromboembolic diseases) as risk factors for miscarriage were categorized into one variable to better interpret the statistical analyses. The demographic and obstetric history data, and prevalence of chronic maternal diseases were analyzed. The following antepartum and intrapartum complications were examined: gestational diabetes mellitus, type 1 diabetes mellitus (T1DM), preeclampsia (PE), chronic hypertension, uterine fibroids, congenital anomalies of the uterus, placental 
abruption, placenta previa, retained placenta, amount of amniotic fluid, premature rupture of the membranes and operative delivery. Neonatal outcome measurements were as follows: gestational age, prematurity, birth weight (BW), fetal growth disturbances (IUGR), small for gestational age (SGA), LBW, VLBW, 1-, 5- and 10-minute Apgar scores, cord arterial blood $\mathrm{pH}$, neonatal intensive care unit (NICU) admission, male sex and congenital abnormalities (see Figure 5).
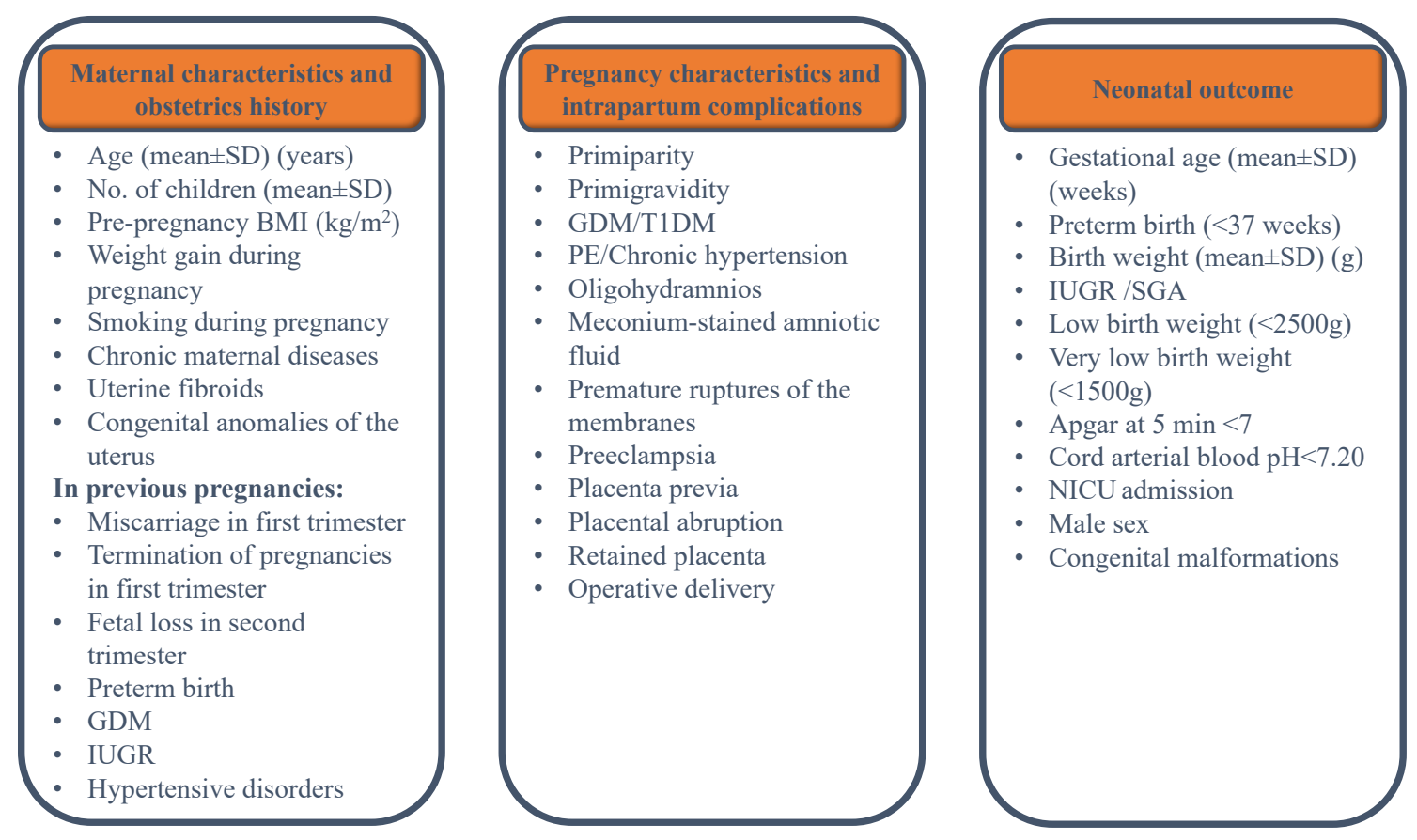

Figure 5. List of collected data on maternal, pregnancy and neonatal characteristics

\subsection{Statistics}

All statistics were calculated using SPSS 22 (SPSS Inc., Chicago, IL, USA). The nonparametric design of the continuous variables was verified with the Shapiro-Wilk test. VT was the major exposure variable. Univariate comparisons between VT pregnancies and controls (Paper 1) and between VT pregnancies (Paper 2) both for IVF/ICSI and spontaneously conceived pregnancies were assessed with the Mann-Whitney U-probe for continuous variables. Categorical variables were compared between the subgroups using $\chi^{2}$ tests, while odds ratios (ORs) and Cornfield's 95\% confidence intervals (CIs) were also calculated. The resultant ORs for IVF and spontaneous pregnancies were compared with Mantel-Haenszel 
tests, providing an estimate of the effect of assisted reproductive techniques on the VT phenomenon. Multivariable logistic regression was performed to evaluate the factors determining VT pregnancies in both the IVF/ICSI and the spontaneous groups separately. NonVT pregnancies were used as the reference group. The multivariable dependence of the target variable on both categorical and continuous data was analyzed using logistic regression with stepwise (forward) model selection based on the likelihood ratio criterion $\left(\mathrm{p}_{\mathrm{in}}=0.05, \mathrm{p}_{\text {out }}=0.10\right)$. All the pre-pregnancy maternal characteristics and perinatal outcome variables represented independent factors. All the variables were adjusted for maternal age, BMI, parity, chronic maternal diseases, and obstetric history data, including miscarriage, termination of pregnancy, fetal loss in the second trimester, hypertensive disorder, prematurity and IUGR in previous pregnancies; all of them constituted confounding risk factors. The adjusted odds ratios (AORs) were also calculated with $95 \% \mathrm{CI}$. All tests were two-tailed, and significance was accepted at $\mathrm{p}<0.05$. $\mathrm{P}$-values were adjusted using the Holm-Bonferroni correction for multiple comparisons (Mann-Whitney U tests and logistic regression analyses).

\section{SUMMARY OF RESULTS}

During the total study period between 1994 and 2016, 67827 singleton and 1615 dichorionic twin live births were registered at the Department of Obstetrics and Gynecology. Of these, 316 were VT live births, exhibiting a rate of 4.53 out of 1,000 total pregnancies. ART was registered from 1992, from the opening of the IVF center in Szeged, and a total of 640 twin pregnancies and 81 VT pregnancies were conceived by ART until the end of the study period. $5.2 \%$ of all singleton deliveries originated from a VT pregnancy after assisted conception, and $0.37 \%$ did so after spontaneous single gestation (Paper 1 ).

The VT live birth rate varied between 36.8 and 28.8/1000 live births in VT pregnancies after IVF/ICSI and was stable at 3.6-3.55/1000 live births in spontaneously conceived VT pregnancies $(\mathrm{p}<0.001)$ (Figure 6). 


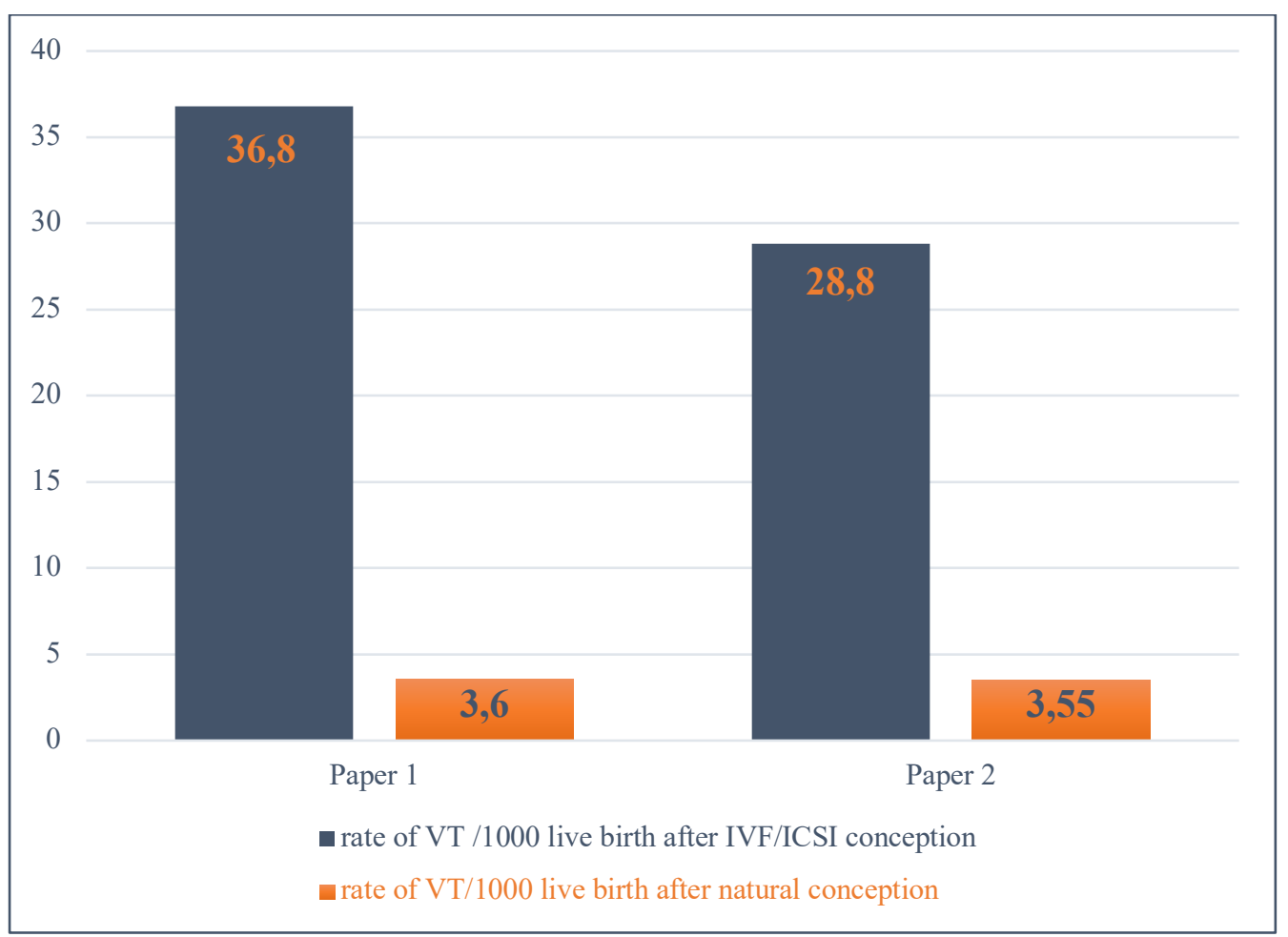

Figure 6. Vanishing twin live birth rate by mode of conception

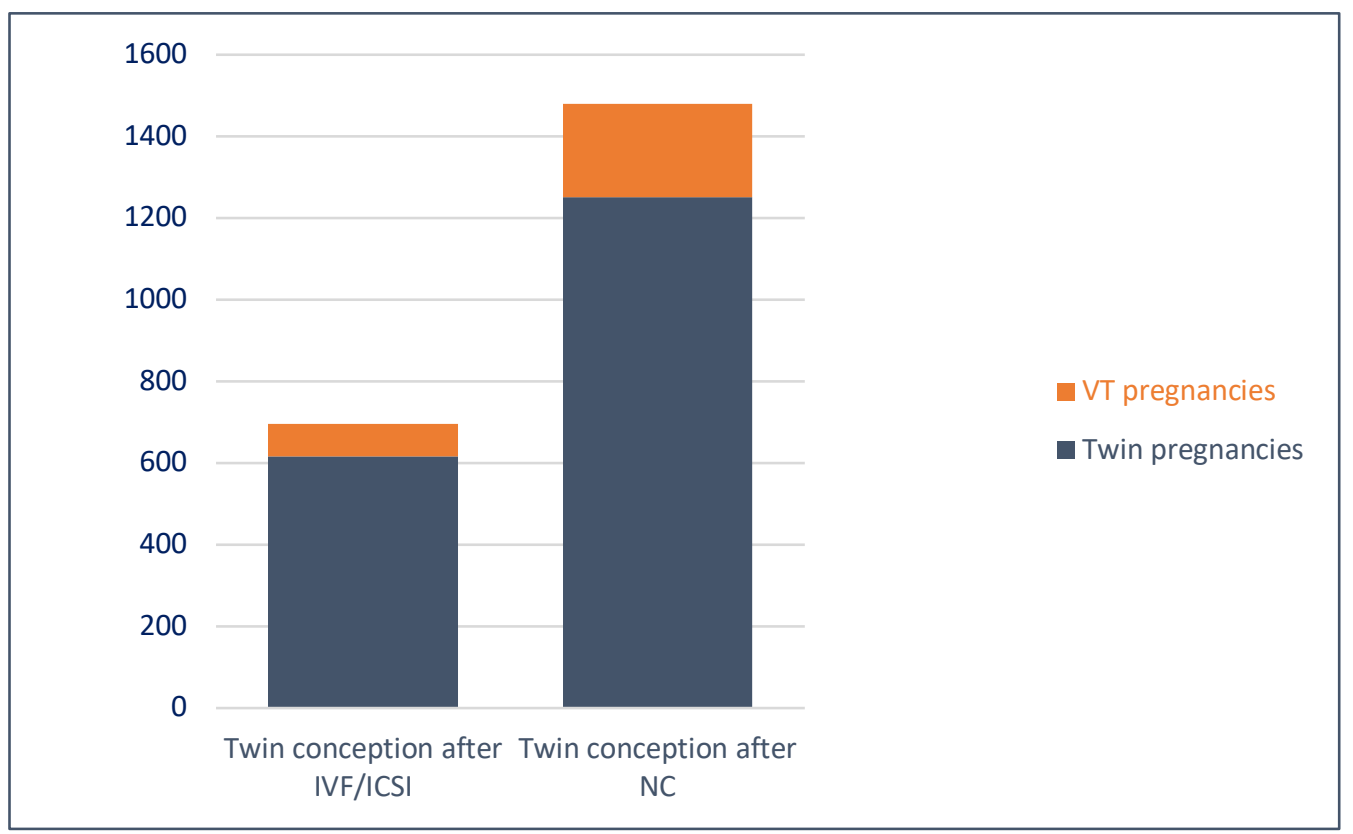

Figure 7. Proportion of VT pregnancies among twins by mode of conception

The proportion of VT pregnancies (Figure 7) among twins was significantly higher after spontaneous conception. 
In Paper 1, 78 VT cases resulting from 617 IVF/ICSI dichorionic twins (12.6\%) and 228 VT cases were naturally conceived for 1252 spontaneous dichorionic twin pregnancies $(18.2 \%)$ $(\mathrm{p}=0.002)$.

In paper 2, $81 \mathrm{VT}$ cases originated from $640 \mathrm{IVF} / \mathrm{ICSI}$ dichorionic twins (12.7\%), and 235 VT cases were conceived without medical assistance for 1301 dichorionic twin pregnancies $(18.1 \%)(\mathrm{p}=0.002)$.

\subsection{Maternal characteristics}

Table 1 presents the patterns for maternal characteristics in the VT pregnancies and their matched singleton pregnancies after IVF/ICSI and natural conception. Maternal obstetric history and characteristics of previous pregnancies were also investigated and compared with control groups (see Table 1).

In Paper 2, the maternal characteristics in VT pregnancies were compared between the two subgroups (as demonstrated in Table 2). Maternal age was higher for the IVF/ICSI pregnancies (mean maternal age: $34.8 \pm 3.71$ ) compared to spontaneously conceived pregnancies (mean maternal age: $33.20 \pm 4.38$ ). All the women in the IVF/ICSI subgroups were non-smokers, and negligibly small proportions $(2.6 \%)$ smoked in the spontaneously conceived subgroups. In Paper 1, BMI at delivery was significantly lower among spontaneous VT pregnant women $(p=0.049)$ than their matched controls, whereas weight gain during pregnancy was similar in the naturally conceived subgroups. All of the chronic maternal diseases examined were significantly more prevalent among VT pregnancies than in the matched control groups. Congenital anomalies of the uterus or fibroids were not observed in the VT groups (data are not presented in the tables). Generally, maternal and neonatal morbidity in previous pregnancies was less frequent among IVF/ICSI mothers due to a low percentage of previous pregnancies. The number of previous miscarriages was not different in VT and non-VT pregnancies, but termination of pregnancy and second-trimester fetal loss previously came into prominence as risk factors for single fetal loss. IUGR in a previous pregnancy was associated with a significantly higher risk of VT in the spontaneous group, but there was no recorded IUGR in the previous IVF/ICSI pregnancies. However, previous maternal diabetes was an independent contributing factor to VT pregnancy in IVF/ICSI pregnancies, whereas it was not a significant determinant in the spontaneous group. 


\begin{tabular}{|c|c|c|c|c|c|c|c|c|c|c|c|c|c|c|c|}
\hline & \multicolumn{4}{|c|}{$\begin{array}{c}\text { Pregnancies after } \\
\text { IVF/ICSI }\end{array}$} & \multirow{3}{*}{ p-value ${ }^{a}$} & \multirow{3}{*}{ Unadjusted $O^{2}{ }^{2}$} & \multirow{3}{*}{ Adjusted $\mathrm{OR}^{\mathrm{a}}$} & \multicolumn{4}{|c|}{$\begin{array}{l}\text { Spontaneously conceived } \\
\text { pregnancies }\end{array}$} & \multirow{3}{*}{ p-value ${ }^{a}$} & \multirow{3}{*}{ Unadjusted $\mathrm{OR}^{2}$} & \multirow{3}{*}{ Adjusted $\mathrm{OR}^{\mathrm{a}}$} & \multirow{3}{*}{ p-value ${ }^{b}$} \\
\hline & \multicolumn{2}{|c|}{$\begin{array}{l}\text { Vanishing } \\
\text { twin } \\
\text { pregnancies } \\
\quad(n=78)\end{array}$} & \multicolumn{2}{|c|}{$\begin{array}{l}\text { Matched } \\
\text { singleton } \\
\text { pregnancies } \\
(\mathrm{n}=\mathbf{2 3 4})\end{array}$} & & & & \multicolumn{2}{|c|}{$\begin{array}{c}\text { Vanishing } \\
\text { twin } \\
\text { pregnancies } \\
(\mathbf{n}=\mathbf{2 2 8})\end{array}$} & \multicolumn{2}{|c|}{$\begin{array}{c}\text { Matched } \\
\text { singleton } \\
\text { pregnancies } \\
(\mathbf{n}=684)\end{array}$} & & & & \\
\hline & $\mathrm{n}$ & $\%$ & $\mathrm{n}$ & $\%$ & & & & $\mathrm{n}$ & $\%$ & $\mathrm{n}$ & $\%$ & & & & \\
\hline $\operatorname{Age}(\operatorname{mean} \pm \mathbf{S D})^{\mathrm{c}}$ & \multicolumn{2}{|c|}{$34.8 \pm 3.71$} & \multicolumn{2}{|c|}{$35.4 \pm 3.74$} & 0.46 & $0.96(0.90-1.03)$ & $0.89(0.86-0.94)$ & \multicolumn{2}{|c|}{$33.20 \pm 4.38$} & \multicolumn{2}{|c|}{$33.30 \pm 4.46$} & 0.85 & $0.99(0.96-1.03)$ & $0.91(0.78-1.14)$ & \\
\hline $\begin{array}{l}\text { No. of children } \\
(\operatorname{mean} \pm \mathrm{SD})^{\mathrm{c}}\end{array}$ & \multicolumn{2}{|c|}{$0.15 \pm 0.37$} & \multicolumn{2}{|c|}{$0.15 \pm 0.36$} & 1.00 & $1.00(0.49-2.04)$ & $1.00(0.65-1.81)$ & \multicolumn{2}{|c|}{$0.71 \pm 0.83$} & \multicolumn{2}{|c|}{$0.74 \pm 0.85$} & 0.86 & $0.96(0.81-1.15)$ & \multicolumn{2}{|l|}{$0.87(0.77-1.34)$} \\
\hline $\begin{array}{c}\text { Pre-pregnancy BMI } \\
\left(\mathrm{kg} / \mathrm{m}^{2}\right)^{\mathrm{c}}\end{array}$ & \multicolumn{2}{|c|}{$23.22 \pm 3.10$} & \multicolumn{2}{|c|}{$23.54 \pm 3.96$} & 0.53 & $0.94(0.87-1.01)$ & $0.93(0.85-1.06)$ & \multicolumn{2}{|c|}{$24.27 \pm 3.44$} & \multicolumn{2}{|c|}{$24.53 \pm 4.90$} & 0.30 & $1.01(0.98-1.05)$ & $1.00(0.95-1.09)$ & \\
\hline $\begin{array}{l}\text { Weight gain during } \\
\text { pregnancy }\end{array}$ & \multicolumn{2}{|c|}{$12.54 \pm 3.95$} & \multicolumn{2}{|c|}{$11.85 \pm 4.87$} & 0.38 & $0.99(0.96-1.01)$ & $1.00(0.91-1.08)$ & \multicolumn{2}{|c|}{$12.34 \pm 5.08$} & \multicolumn{2}{|c|}{$13.24 \pm 5.29$} & 0.39 & $0.97(0.96-1.02)$ & \multicolumn{2}{|l|}{$0.95(0.91-1.05)$} \\
\hline $\begin{array}{c}\text { Smoking during } \\
\text { pregnancy }\end{array}$ & 0 & 0 & 0 & 0 & $\therefore$ & $\therefore$ & $\therefore$ & 6 & 2.6 & 36 & 5.3 & 0.67 & $0.49(0.20-1.17)$ & $0.33(0.11-1.45)$ & 0.92 \\
\hline $\begin{array}{c}\text { Chr.maternal } \\
\text { diseases }^{\mathrm{d}}\end{array}$ & 15 & 19.2 & 18 & 7.7 & 0.009 & $2.86(1.36-6.00)$ & $1.10(1.10-2.20)$ & 54 & 23.7 & 90 & 13.2 & $<0.001$ & $2.05(1.41-2.99)$ & $2.01(1.56-2.67)$ & 0.97 \\
\hline \multirow{3}{*}{ Previous pregnancy" } & $\begin{array}{r}\text { Tota } \\
\text { pre }\end{array}$ & $\begin{array}{l}\text { number } \\
\text { nancies : }\end{array}$ & $\begin{array}{l}\text { of mult } \\
\text { fter IV }\end{array}$ & $\begin{array}{l}\text { arous } \\
\text { ICSI }\end{array}$ & & & & $\begin{array}{r}\text { Total } \\
\mathrm{p}\end{array}$ & $\begin{array}{l}\text { number } \\
\text { egnancie }\end{array}$ & $\begin{array}{l}\text { of multi } \\
\text { is after }\end{array}$ & & & & & \\
\hline & $\begin{array}{r}\text { Vanisl } \\
\text { preg }\end{array}$ & $\begin{array}{l}\text { ng twin } \\
\text { ancies }\end{array}$ & $\begin{array}{r}\mathrm{Ma} \\
\text { sin } \\
\text { preg } \\
\text { (n }\end{array}$ & $\begin{array}{l}\text { :hed } \\
\text { : ton } \\
\text { tncies }\end{array}$ & & & & $\begin{array}{r}\text { Vanish } \\
\text { pregr }\end{array}$ & $\begin{array}{l}\text { ing twin } \\
\text { ancies }\end{array}$ & $\begin{array}{r}\text { Mat } \\
\text { sing } \\
\text { pregn }\end{array}$ & $\begin{array}{l}\text { ched } \\
\text { eton } \\
\text { ancies }\end{array}$ & & & & \\
\hline & $\mathrm{n}$ & $\%$ & $\mathrm{n}$ & $\%$ & & & & $\mathrm{n}$ & $\%$ & $\mathrm{n}$ & $\%$ & & & & \\
\hline $\begin{array}{c}\text { Miscarriage in first } \\
\text { trimester }\end{array}$ & 18 & 100 & 54 & 100 & $\therefore$ & $\therefore$ & $\therefore$ & 66 & 45.8 & 174 & 42 & 0.44 & $1.17(0.80-1.71)$ & $1.34(0.80-2.82)$ & 0.98 \\
\hline $\begin{array}{c}\text { Termination of } \\
\text { pregnancies in first } \\
\text { trimester }\end{array}$ & 0 & 0 & 0 & 0 & $\therefore$ & $\therefore$ & $\therefore$ & 66 & 45.8 & 144 & 34.8 & 0.02 & $1.59(1.08-2.33)$ & $1.34(1.10-2.82)$ & 0.51 \\
\hline $\begin{array}{l}\text { Fetal loss in second } \\
\text { trimester }\end{array}$ & 0 & 0 & 0 & 0 & $\therefore$ & $\therefore$ & - & 18 & 12.5 & 18 & 4.3 & 0.001 & $3.14(1.59-6.23)$ & $3.32(1.80-7.82)$ & 0.72 \\
\hline Preterm birth & 0 & 0 & 6 & 11.1 & 0.33 & $0.89(0.81-0.97)$ & (0.66) $0.70(0.54-0.79)$ & 12 & 8.3 & 24 & 5.8 & 0.32 & $1.48(0.72-3.04)$ & $1.77(0.90-2.24)$ & 0.98 \\
\hline IUGR & 0 & 0 & 0 & 0 & $\therefore$ & $\therefore$ & $\therefore$ & 18 & 12.5 & 0 & 0 & $<0.001$ & $1.14(1.07-1.21)$ & $1.22(1.20-1.34)$ & 0.59 \\
\hline $\begin{array}{l}\text { Hypertensive } \\
\text { disorders }\end{array}$ & 0 & 0 & 0 & 0 & $\therefore$ & $\therefore$ & - & 0 & 0 & 24 & 5.8 & 0.001 & $0.94(0.92-0.97)$ & $0.12(0.10-0.44)$ & 0.82 \\
\hline $\begin{array}{c}\text { Gestational diabetes } \\
\text { mellitus }\end{array}$ & 6 & 33.3 & 6 & 11.1 & 0.06 & $4.00(1.09-14.6)$ & $3.1(1.88-10.1)$ & 6 & 4.2 & 22 & 5.3 & 0.66 & $0.78(0.31-1.95)$ & $1.22(0.91-1.29)$ & 0.98 \\
\hline
\end{tabular}

Table 1. Baseline maternal characteristics and obstetric history in pregnancies complicated by vanishing twins and matched controls 


\begin{tabular}{|c|c|c|c|c|c|c|c|}
\hline & \multirow{2}{*}{\multicolumn{2}{|c|}{$\begin{array}{l}\text { Pregnancies } \\
\text { after IVF/ICSI } \\
\qquad(\mathbf{n}=\mathbf{8 1})\end{array}$}} & \multirow{2}{*}{\multicolumn{2}{|c|}{$\begin{array}{c}\text { Pregnancies after } \\
\text { NC } \\
(\mathbf{n}=\mathbf{2 3 5})\end{array}$}} & \multirow{3}{*}{ p-value ${ }^{b}$} & \multirow{3}{*}{ Unadjusted $O R^{b, d}$} & \multirow{3}{*}{ Adjusted $\mathrm{OR}^{\mathrm{b}, \mathrm{c}, \mathrm{d}}$} \\
\hline & & & & & & & \\
\hline & $\mathrm{n}$ & $\%$ & $\mathrm{n}$ & $\%$ & & & \\
\hline Age $\left(\right.$ years) ${ }^{\mathrm{a}}$ & \multicolumn{2}{|c|}{$34.8 \pm 3.7$} & \multicolumn{2}{|c|}{$33.2 \pm 4.3$} & 0.003 & $1.1(1.03-1.8)$ & $1.2(1.1-2.12)$ \\
\hline Primigravidity & 62 & 76.5 & 85 & 36.2 & $<0.001$ & $5.76(3.23-10.3)$ & $5.5(2.12-11.31)$ \\
\hline Primiparity & 74 & 91.4 & 111 & 47.2 & $<0.001$ & $11.81(5.22-26.71)$ & $9.10(3.49-21.2)$ \\
\hline Number of children ${ }^{a}$ & \multicolumn{2}{|c|}{$0.2 \pm 0.4$} & \multicolumn{2}{|c|}{$0.7 \pm 0.8$} & $<0.001$ & $0.23(0.13-0.41)$ & $0.33(0.14-0.84)$ \\
\hline $\begin{array}{c}\text { Previous termination of } \\
\text { pregnancy }\end{array}$ & 0 & 0 & 67 & 28.5 & $<0.001$ & $0.72(0.66-0.78)$ & $0.56(0.31-0.77)$ \\
\hline $\begin{array}{l}\text { Total No. of previous } \\
\text { terminations of } \\
\text { pregnancya }\end{array}$ & \multicolumn{2}{|c|}{0} & \multicolumn{2}{|c|}{$0.5 \pm 0.8$} & $<0.001$ & $0.57(0.12-0.89)$ & $0.40(0.19-0.93)$ \\
\hline Previous miscarriage & 19 & 23.5 & 70 & 29.8 & 0.32 & $0.72(0.40-1.30)$ & $0.81(0.21-1.91)$ \\
\hline $\begin{array}{l}\text { Total No.of previous } \\
\text { miscarriages }\end{array}$ & \multicolumn{2}{|c|}{$0.3 \pm 0.6$} & \multicolumn{2}{|c|}{$0.4 \pm 0.7$} & 0.43 & $0.85(0.56-1.28)$ & $0.78(0.34-1.59)$ \\
\hline $\begin{array}{c}\text { Previous } 2^{\text {nd }} \text {. } \\
\text { trim.abortion/miscarriage }\end{array}$ & 0 & 0 & 18 & 7.7 & 0.005 & $0.92(0.89-0.96)$ & $0.67(0.45-0.89)$ \\
\hline Pre-pregnancy BMI ${ }^{\mathrm{a}}$ & \multicolumn{2}{|c|}{$23.3 \pm 3.1$} & \multicolumn{2}{|c|}{$23.5 \pm 4.0$} & 0.67 & $0.98(0.92-1.06)$ & $0.90(0.81-1.21)$ \\
\hline $\begin{array}{l}\text { Weight gain during } \\
\text { pregnancy }(\mathrm{kg}) \mathrm{a}\end{array}$ & \multicolumn{2}{|c|}{$12.4 \pm 3.9$} & \multicolumn{2}{|c|}{$12.3 \pm 5.0$} & 0.81 & $1.01(0.96-1.06)$ & $1.11(0.89-1.23)$ \\
\hline \multirow[t]{3}{*}{$\begin{array}{c}\text { Smoking during } \\
\text { pregnancy }\end{array}$} & 0 & 0 & 6 & 2.6 & 0.34 & $0.97(0.95-1.99)$ & $0.81(0.49-2.31)$ \\
\hline & \multicolumn{2}{|c|}{$\begin{array}{c}\text { Pregnancies } \\
\text { after IVF/ICSI } \\
(\mathbf{n}=\mathbf{8 1})\end{array}$} & \multicolumn{2}{|c|}{$\begin{array}{l}\text { Pregnancies after } \\
\text { spontaneous } \\
\text { conception }(n=235)\end{array}$} & \multirow[t]{2}{*}{ p-value } & \multirow[t]{2}{*}{$\begin{array}{l}\text { Unadjusted OR } \\
\qquad(95 \% \text { CI })^{b, d}\end{array}$} & \multirow[t]{2}{*}{$\begin{array}{l}\text { Adjusted OR } \\
(95 \% \mathrm{CI})^{\mathrm{b}, \mathrm{c}, \mathrm{d}}\end{array}$} \\
\hline & $\mathrm{n}$ & $\%$ & $\mathrm{n}$ & $\%$ & & & \\
\hline \multicolumn{8}{|c|}{ Complications in previous pregnancies } \\
\hline GDM & 6 & 7.4 & 0 & 0 & $<0.001$ & $1.08(1.01-1.15)$ & $3.21(1.91-9.4)$ \\
\hline IUGR & 0 & 0 & 18 & 7.7 & 0.005 & $0.92(0.89-0.96)$ & $0.10(0.09-0.71)$ \\
\hline Prematurity & 0 & 0 & 12 & 5.1 & 0.041 & $0.95(0.92-0.98)$ & $0.31(0.12-0.78)$ \\
\hline $\begin{array}{c}\text { Maternal hypertensive } \\
\text { disorders }\end{array}$ & 0 & 0 & 0 & 0 & 1.00 & n.m.* & n.m. * \\
\hline
\end{tabular}

Table 2. Baseline maternal characteristics and obstetric history in VT pregnancies 
Maternal obstetric history and characteristics of previous pregnancies were also investigated. A comparison with control groups is found in Table 1, and differences between the two VT groups are shown in Table 2. Generally, maternal and neonatal morbidity in previous pregnancies was less frequent among IVF/ICSI mothers due to a low percentage of previous pregnancies. The number of previous miscarriages was not different in VT and nonVT pregnancies, but previous termination of pregnancy and second-trimester fetal loss came into prominence as risk factors for single fetal loss. IUGR in a previous pregnancy was associated with a significantly higher risk of VT in the spontaneous group, but there was no recorded IUGR in the previous IVF/ICSI pregnancies. However, previous maternal diabetes was an independent contributing factor to VT pregnancy in IVF/ICSI pregnancies, whereas it was not a significant determinant in the spontaneous group. Congenital anomalies of the uterus or fibroids were not observed in the VT groups (data are not presented in the tables).

\subsection{Pregnancy characteristics and intrapartum complications}

Tables 3 and 4 display an overview of the pregnancy characteristics and intrapartum complications in the VT groups and matched controls and between the two VT subgroups. In Paper 1, GDM developed in a substantially higher percentage of women with VT pregnancies (odds ratio (OR): 3.0; 95\% CI: 1.6-5.6) than in the non-VT pregnancies after IVF/ICSI $(\mathrm{p}=0.01)$, while it was inversely less common among their naturally conceived counterparts (OR: 0.46; 95\% CI: 0.2-1.1). Even after adjusting for confounders, IVF/ICSI was significantly more associated with GDM; this was more pronounced for VT cases $(p<0.001)$ due to its very low occurrence in the spontaneous group.

Pregestational diabetes mellitus represented an increased risk for VT after IVF/ICSI (Adjusted (A)OR: 1.07; 95\% CI: 1.04-1.2), while it was not a risk for the spontaneously conceived subgroups (AOR: 1.00; 95\% CI: 0.94-1.00), thus exhibiting a significant difference between the IVF/ICSI and non-IVF VT pregnancies $(p<0.001)$. Preeclamptic pregnancies in VT subgroups following IVF/ICSI (AOR: 1.6; 95\% CI: 0.7-6.1) and spontaneous conception (AOR: 1.00; 95\% CI: 0.8-1.8) showed similar proportions compared to matched controls.

Placentation abnormalities presented in Papers 1 and 2 were more frequent in VT pregnancies after IVF/ICSI than their counterparts who conceived spontaneously. Placenta previa was significantly more frequent in VT pregnancies after IVF/ICSI than after natural conception $(p<0.001)$ and almost significantly more prevalent in VT pregnancies in the 
IVF/ICSI group ( $p=0.08$, AOR: $3.8 ; 95 \% \mathrm{CI}: 1.0-9.3$ ) compared to the non-VT IVF/ICSI subgroup. The occurrence of retained placenta was significantly more frequent in VT pregnancies after IVF/ICSI (AOR: 7.2; 95\% CI: 3.1-19) compared to matched controls or spontaneous pregnancies (AOR: 0.67; 95\% CI: 0.3-1.2). There was a negligible low occurrence of placental abruption among VT pregnancies. Although the spontaneous VT pregnancies were significantly more likely to be complicated by placental abruption than the matched controls (AOR: 10.6; 95\% CI: 2.5-39), this was less marked after IVF/ICSI (AOR: 3.6; 95\% CI: 1.59). The incidences of operative deliveries were non-significantly lower among the IVF/ICSI pregnancies compared to their spontaneously conceived counterparts.

The average gestational length at the time of vanishing in the IVF/ICSI group was $9.86 \pm 2.06$ weeks, whereas VT was confirmed at $8.86 \pm 2.70$ weeks in the spontaneous group $(p=0.057)($ data not shown). 


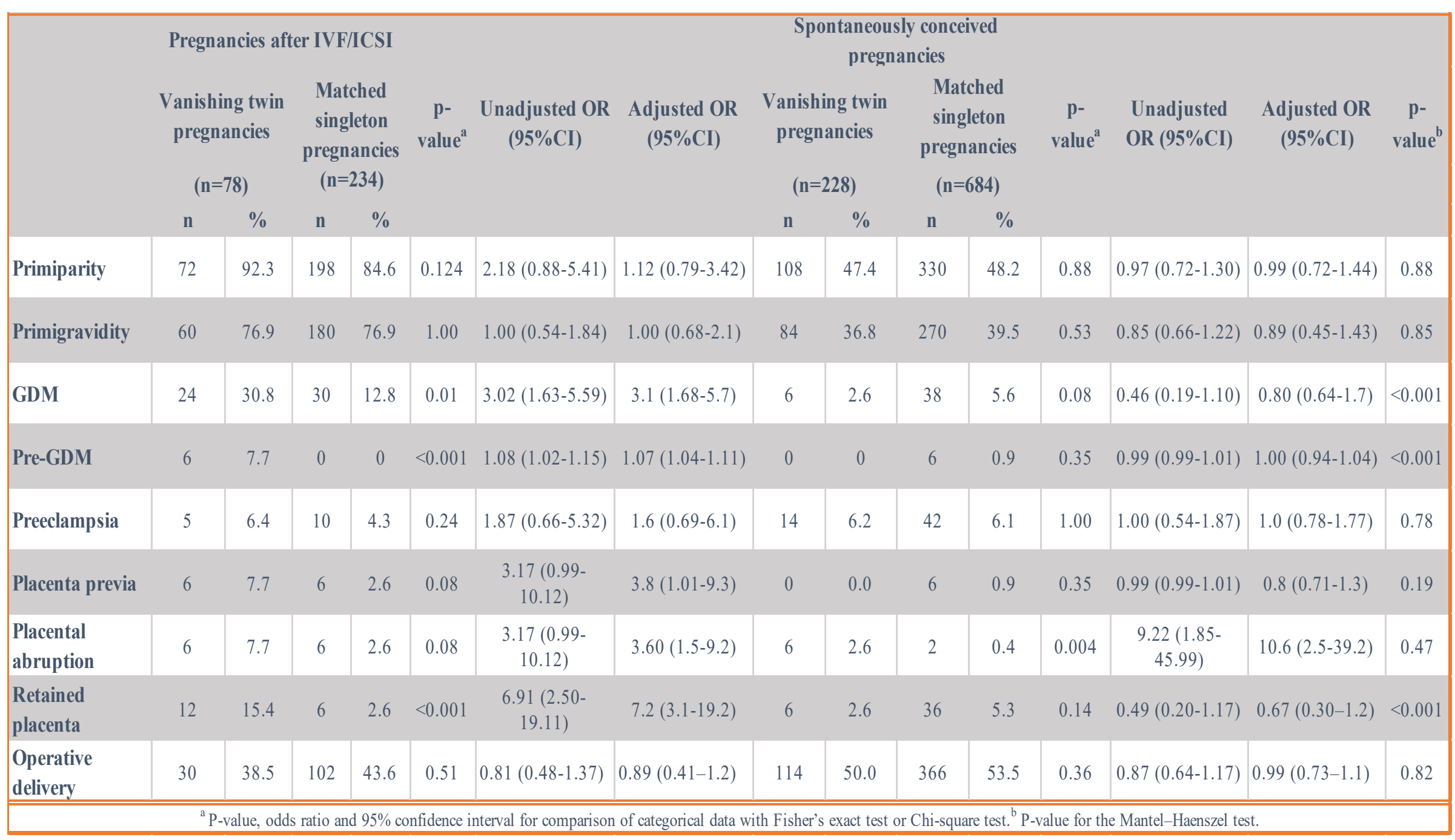

Table 3. Pregnancy characteristics and intrapartum complications in pregnancies complicated by vanishing twins 


\begin{tabular}{|c|c|c|c|c|c|c|c|}
\hline & \multicolumn{2}{|c|}{$\begin{array}{c}\text { Pregnancies after } \\
\text { IVF/ICSI } \\
(\mathbf{n}=\mathbf{8 1})\end{array}$} & \multicolumn{2}{|c|}{$\begin{array}{l}\text { Spontaneously } \\
\text { conceived } \\
\text { pregnancies } \\
(\mathbf{n}=\mathbf{2 3 5})\end{array}$} & \multirow[t]{2}{*}{ p-value ${ }^{a}$} & \multirow[t]{2}{*}{$\begin{array}{l}\text { Unadjusted } \\
\mathrm{OR}^{\mathrm{a}, \mathrm{b}}\end{array}$} & \multirow[t]{2}{*}{ Adjusted $\mathbf{O R}^{\mathrm{b}, \mathrm{c}}$} \\
\hline & $\mathbf{n}$ & $\%$ & $\mathbf{n}$ & $\%$ & & & \\
\hline $\begin{array}{c}\text { Gestational } \\
\text { diabetes mellitus }\end{array}$ & 24 & 29.6 & 7 & 3.0 & $<0.001$ & $\begin{array}{c}13.7 \\
(5.63-33.4)\end{array}$ & $\begin{array}{c}11.1 \\
(6.72-32.12)\end{array}$ \\
\hline $\begin{array}{c}\text { Pre-gestational } \\
\text { diabetes mellitus }\end{array}$ & 6 & 7.4 & 0 & 0 & $<0.001$ & $\begin{array}{c}1.08 \\
(1.01-1.15)\end{array}$ & $4.12(2.12-6.89)$ \\
\hline Preeclampsia & 0 & 0 & 6 & 2.6 & 0.34 & $\begin{array}{c}0.97 \\
(0.96-1.00)\end{array}$ & $0.34(0.19-0.49)$ \\
\hline Placenta previa & 6 & 7.4 & 0 & 0 & $<0.001$ & $\begin{array}{c}1.08 \\
(1.01-1.15)\end{array}$ & $2.91(1.10-8.21)$ \\
\hline Uterine inertia & 49 & 60.5 & 96 & 40.9 & 0.003 & $\begin{array}{c}2.22 \\
(1.32-3.71)\end{array}$ & $1.73(1.47-4.21)$ \\
\hline Malposition & 0 & 0 & 18 & 7.7 & 0.005 & $\begin{array}{c}0.92 \\
(0.89-0.96)\end{array}$ & $0.63(0.12-0.81)$ \\
\hline Oligohydramnios & 6 & 7.4 & 18 & 7.7 & 1.00 & $\begin{array}{c}0.96 \\
(0.37-2.52)\end{array}$ & $1.02(0.78-2.20)$ \\
\hline $\begin{array}{l}\text { Meconium-stained } \\
\text { amniotic fluid }\end{array}$ & 13 & 16.0 & 18 & 7.7 & 0.049 & $\begin{array}{c}2.31 \\
(1.07-4.95)\end{array}$ & $1.89(1.09-3.12)$ \\
\hline $\begin{array}{l}\text { Premature } \\
\text { ruptures of the } \\
\text { membranes }\end{array}$ & 0 & 0 & 6 & 2.6 & 0.34 & $\begin{array}{c}0.97 \\
(0.96-1.00)\end{array}$ & $0.65(0.21-1.81)$ \\
\hline $\begin{array}{l}\text { Placental } \\
\text { abruption }\end{array}$ & 6 & 7.4 & 6 & 2.6 & 0.084 & $\begin{array}{c}3.05 \\
(0.96-9.75)\end{array}$ & $2.12(0.78-6.21)$ \\
\hline Retained placenta & 12 & 14.8 & 6 & 2.6 & $<0.001$ & $\begin{array}{c}6.64 \\
(2.40-18.3)\end{array}$ & $7.1(5.1-14.31)$ \\
\hline Prolonged labor & 48 & 59.3 & 97 & 41.3 & 0.006 & $\begin{array}{c}2.07 \\
(1.24-3.46)\end{array}$ & $1.89(1.34-2.89)$ \\
\hline Operative delivery & 31 & 38.3 & 117 & 49.8 & 0.09 & $\begin{array}{c}0.63 \\
(0.37-1.05)\end{array}$ & \\
\hline $\begin{array}{l}\text { a P-value, odds ratio and } 9 \\
\text { Mann-Whitney U tests to } \\
\text { were adjusted for age, BMI, } \\
\text { in the second trimester, hy }\end{array}$ & 6 con & terval & ompar & $\begin{array}{l}\text { categ } \\
\text { les. }{ }^{\text {b }}( \\
\text { etric } 1\end{array}$ & $\begin{array}{l}\text { l data witl } \\
\text { CI): Cornf } \\
\text { ry data: } m\end{array}$ & $\begin{array}{l}\text { her's exact test o } \\
\text { s } 95 \% \text { confidenc } \\
\text { riage, terminatior }\end{array}$ & $\begin{array}{l}\text { Chi-square test and for } \\
\text { intervals. }{ }^{c} \text { All variable } \\
\text { f pregnancy, fetal loss }\end{array}$ \\
\hline
\end{tabular}

Table 4. Pregnancy characteristics and intrapartum complication in pregnancies complicated by vanishing twins 


\subsection{Neonatal outcomes}

The differences in neonatal outcomes in the VT and matched control subgroups are shown in Table 5 and in VT groups by mode of conception in Table 6. Similar gestational age at time of delivery was noted in all of the study groups. In Paper 1, the incidences of preterm birth were equally low among VT cases and controls in both subgroups. Furthermore, there were no very preterm deliveries in the study groups. In Paper 2, unexpectedly, the rate of preterm birth was higher among spontaneously conceived VT cases than after the IVF/ICSI procedure.

The rate of IUGR (Paper 1) was statistically higher in the VT pregnancies in the spontaneous group (AOR: 3.0; 95\% CI: 1.8-5.2) and even more so among the IVF/ICSI cases compare to the control groups (AOR: 9.2; 95\% CI: 5-22). Comparing the prevalence of IUGR (Paper 2) between the two VT groups, it is significantly higher in the IVF/ICSI group than in their spontaneously conceived counterparts.

The incidences of low birth weight were threefold higher in the IVF/ICSI VT pregnancies and two times higher in the naturally conceived VT pregnancies compared to the control groups (Paper 1). Comparing the incidence of LBW between the two VT subgroups in Paper 2, the rate was significantly higher in the IVF/ICSI VT group than in their spontaneously conceived counterparts. There were no IVF/ICSI VT pregnancies registered as very low birth weight, and the rate was extremely scant in the spontaneous VT group.

The proportion of macrosomia was slightly lower in the VT pregnancies than in the controls in the IVF/ICSI group, but VT was associated with a significantly lower rate of macrosomia after spontaneous conception (Paper 1).

The VT phenomenon in Paper 1 resulted in a significantly higher male sex rate in spontaneous pregnancies (AOR: 1.4; 95\% CI: 1.2-1.9) but not in the IVF/ICSI group (AOR: 1.1; 95\% CI: 0.8-1.9). Unlike in Paper 2, the study groups presented a similar neonatal gender rate.

In Paper 1, the frequencies of NICU admission were not more common in the VT cases; however, in Paper 2, a significantly higher rate of NICU admission was found in the spontaneously conceived VT group than in the IVF/ICSI VT group. 


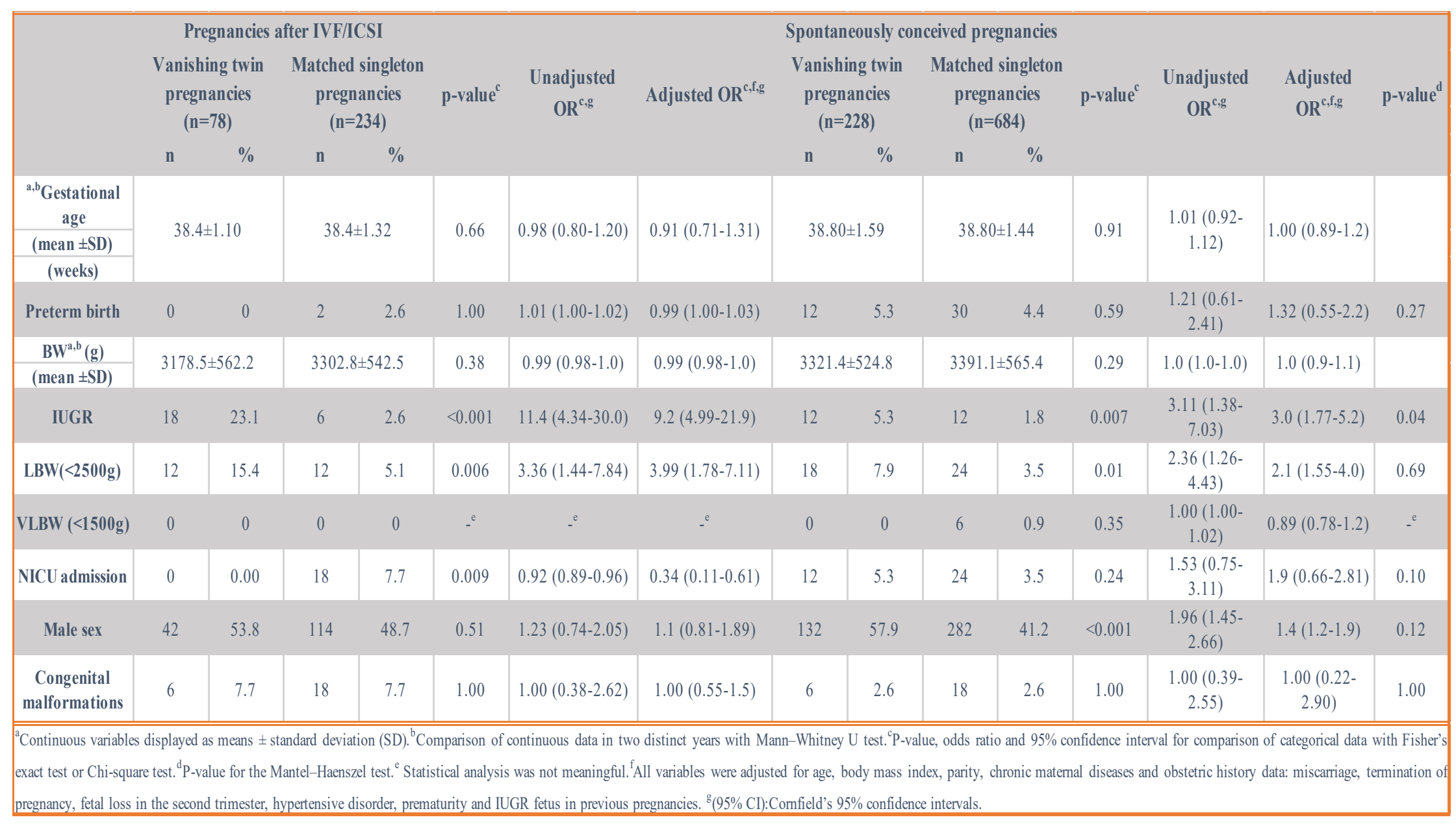

Table 5. Neonatal outcome in pregnancies complicated by vanishing twins and matched controls 
The umbilical cord blood analysis had shown a higher prevalence of acidemia (umbilical artery $\mathrm{pH}$ less than 7.20) in the IVF/ICSI VT group, but the 5-min Apgar scores, another independent marker for neonatal outcome, had not shown the same unfavorable results (Paper 2). The frequencies of congenital malformation reported were not common in the VT cases; the rate was higher among those who conceived after assisted reproductive techniques but did not reach statistical significance.

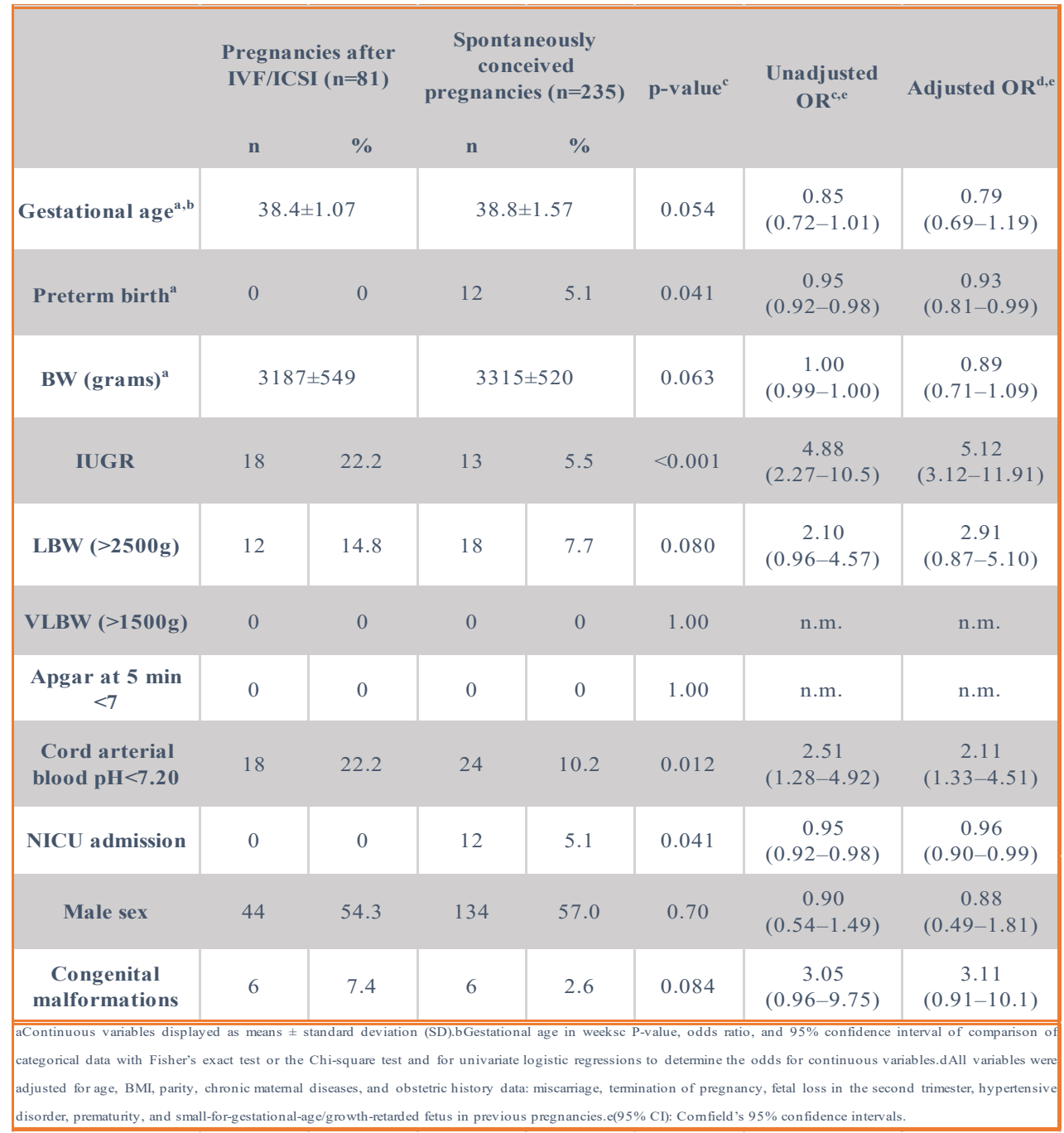

Table 6. Neonatal outcome in pregnancies complicated by vanishing twins achieved by IVF/ICSI vs. spontaneous conception 


\subsection{Independent risk factors associated with the vanishing twin phenomenon}

In Table 7, the results of the multiple logistic regression analyses pointed out the different risk factor structure for VT pregnancies achieved by ART and natural conception (Paper 1). Previous and present GDM influenced the occurrence of VT in the IVF/ICSI group with AORs of 5.41 and 2.33, respectively, while chronic maternal disease was also a predictor, with an AOR of 3.48. The women with IVF/ICSI VT pregnancies had an overall 4.35-fold higher risk of placental abruption. Within the IVF/ICSI VT group, there was an 8.00-fold higher risk of retained placenta and a 28.2-fold higher risk of an IUGR neonate. The risk of VT rose to 2.10-fold when a chronic maternal disease was present, and the surviving fetus had 3.65-fold higher odds for IUGR in spontaneous VT pregnancies.

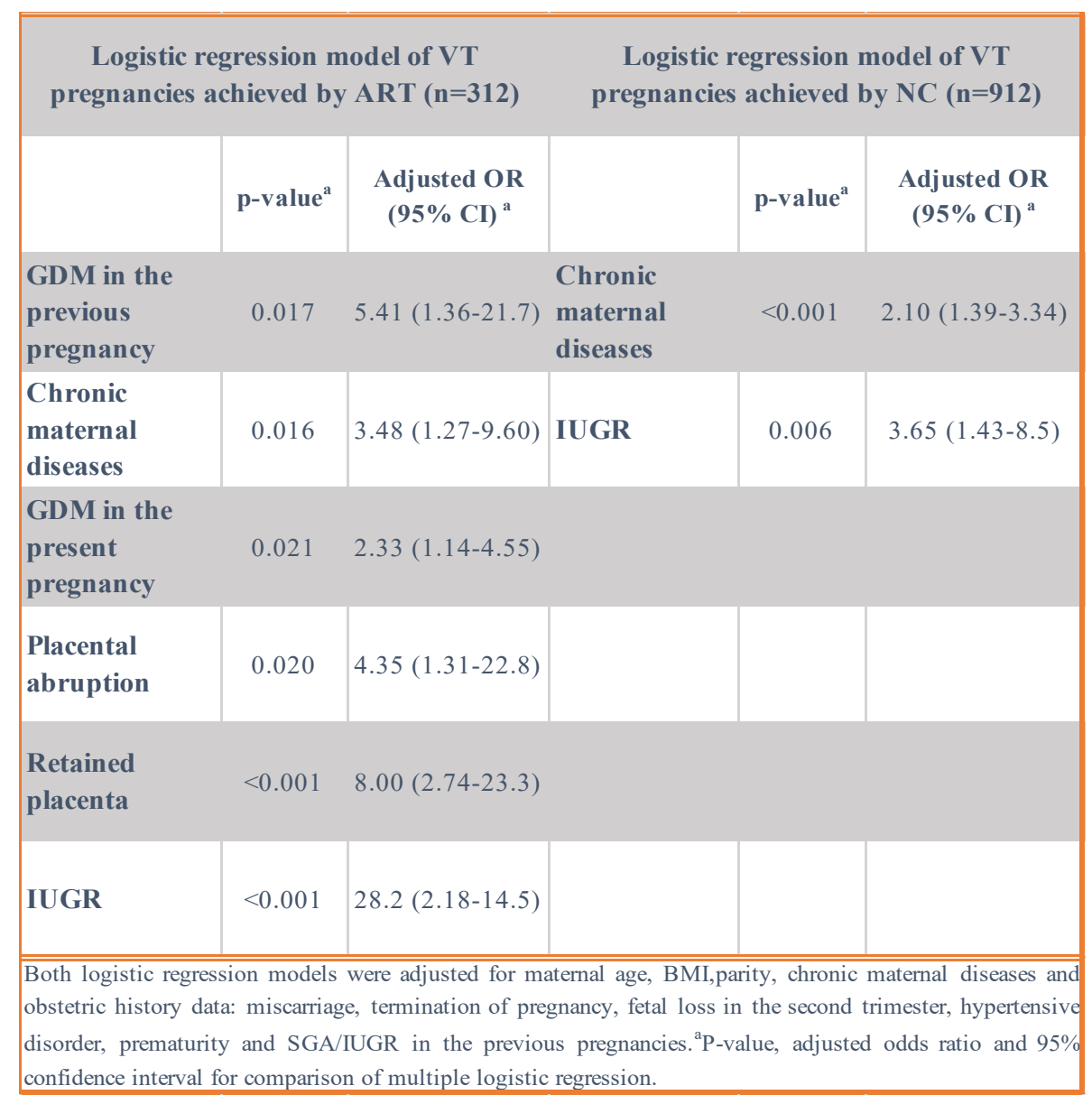

Table 7 Logistic regression models on presenting risk factors of vanishing twin pregnancies 
In Paper 2, multivariable regression analysis was also performed, with factors associated with the infertility treatment among those with VT pregnancies summarized in Table 8. Women were significantly older (AOR: 1.30) and primiparity was also a predictor with an OR of 3.8 in the IVF/ICSI group. Like the results in the first study, GDM and hypertensive disorders developed at a substantially higher percentage of pregnant women with VT pregnancies following IVF/ICSI (AOR: 2.10 and 3.54, respectively). VT pregnancies after ART had an increased risk of placenta anomalies (placental abruption with an AOR of 4.9 and retained placenta with an AOR of 5.69). Mode of conception was a distinguishable determinant in BW, and neonates after IVF/ICSI had a lower BW even after controlling for relevant cofactors (AOR: 0.98). The neonates after IVF/ICSI VT pregnancies had an overall 1.10-fold higher risk of unfavorable arterial cord blood $\mathrm{pH}$ and an AOR of 1.13 for prolonged labor.

\begin{tabular}{|c|c|c|}
\hline \hline & p-value & Adjusted OR (95\% \\
\hline \multicolumn{2}{|c|}{ CI) }
\end{tabular}




\section{DISCUSSION OF SPECIFIC RESULTS AND COMPARISON WITH OTHER STUDIES}

The principal finding of the present study is that VT carries a higher risk of various pregnancy complications, particularly following the IVF/ICSI procedure.

Embryonic loss has a significant effect on more twin pregnancies after natural implantation (18.2\%) than after the iatrogenic transfer of two embryos (12.6\%). Our results correspond to the VT rates among twins after IVF/ICSI reported in the literature (between $10.8 \%$ and $39.0 \%)$ [11], [28], [34], [35].

Early pregnancy loss and the VT phenomenon both share a chromosomal defect in the conceptus [31], [32], and this explains the fact that the artificial selection procedure for morphologically normal embryos decreases the rate of VT after IVF/ICSI. Other possible explanations could be the fresh embryo transfer, which is associated with a higher perinatal risk [43]. The incidence of VT pregnancies increases with maternal age due to a higher risk of chromosomal abnormalities in the oocytes, which is the strongest predictor of embryo potential [44]. After natural conception without any embryo selection, age-related chromosomal abnormalities and the derived embryo pose a higher risk of VTS in advanced maternal age.

Maternal age influences the development of VT pregnancies in two other ways: the frequency of dichorionic twins rises with maternal age due to superovulation after spontaneous conception [45], and advanced maternal age leads to an increasing use of IVF procedures with the consequences of multiple embryo transfers. In line with the concept that twinning frequency increases with maternal age [46], [47], we found that the VT phenomenon is also associated with advanced age in both groups in IVF/ICSI pregnancies, as documented by others [11], [31].

Although the VT phenomenon occurs more often after natural conception, the prevalence of VTS is significantly higher among twins after ART. In our study (Paper 1), 5.2\% of all singleton deliveries originated from a VT pregnancy after assisted conception, and only $0.37 \%$ did so after spontaneous single gestation. The observed difference in the incidences of VT supports the idea that an artificial selection procedure favors embryos with high developmental potential [31], [32]. This raises the possible higher risk of the implantation of a genetically impaired vanishing embryo in naturally conceived pregnancies, as suggested earlier [32]. Further, transfer of an intermediate-quality embryo increases the chance of VT [31]. Other explanations for this difference are the technology itself [48] or the artificially modified 
endometrium [49] in assisted reproductive cycles. Although a moderately thick endometrium with a triple-line pattern is more likely linked to a good clinical outcome, the decidualized endometrium acts as a biosensor of embryo quality and the interaction between the mucosa and the embryo with inadequate quality might coordinate the VT phenomenon [51].

An adverse obstetric history comprising induced abortion and second-trimester fetal loss as classical miscarriage-related factors is also strongly associated with single loss in twins in spontaneous pregnancies. Miscarriage-related risk factors, such as obesity and smoking, do not seem to play a role in VT because of the possible effect on both embryos. Nor does it appear that cavity deformities, such as congenital uterine anomalies, account for VT.

Another major finding of the thesis is that chronic maternal diseases and a history of certain high-risk pregnancies (e.g. IUGR and GDM) might contribute to the absorption of a single embryo in twin pregnancy, particularly in IVF/ICSI pregnancies. This further emphasizes the detrimental effect of the greater pre-pregnancy susceptibility pertaining directly to the inherent factors in the pathomechanism of the VT phenomenon. Moreover, the increased risk of adverse perinatal outcome could be attributed partly to assisted reproductive technology and background infertility [35], [48], [50] as well. The influence of assisted reproductive procedures (ICSI), such as the culture medium, the ovarian hyperstimulation and the effects of fertility drugs on fetal growth and development, has been an ongoing debate. A major topic is whether ART disrupts imprinted gene regulation [51], [52].

An important observation is that a significantly higher recurrence rate for GDM and an increased incidence of pre-gestational and gestational diabetes mellitus was found among IVF/ICSI VT pregnancies, which is in line with the fact that IVF/ICSI presents a higher risk for diabetes mellitus than spontaneous conception [53].

On the other hand, one potential relationship between diabetes mellitus and the VT phenomenon could be the relative uteroplacental insufficiency due to the impairment of early placental development and placental "crowding". Placental development is responsible for fetal intrauterine growth, especially in multiple gestation; further, the early simultaneity and competition of the placentas [54], [55] exceed the uterine capacity, leading to relative uteroplacental insufficiency and intrauterine growth disturbances [25], which develop rather early in diabetic pregnancies [56]. Diabetes-generated teratogens might also induce miscarriage [57], which might even lead to the loss of one infant from a pair of twins possibly due to the uneven susceptibilities of the fetuses. 
In accordance with other studies [29], [42], we found that placental dysfunction caused by hypertensive disorders appears not to determine the outcome of VT pregnancies considerably since essential hypertension is extremely uncommon. There does not seem to be any link between VT and PE.

Placentation anomalies, such as placenta previa, placental abruption and retained placenta associated with VT via the reduced uteroplacental flow, represent a further factor that seems to contribute to the absorption of a conceptus in a twin pregnancy, particularly in IVF/ICSI pregnancies, and may also contribute to the adverse outcomes of VT pregnancies [48], [50]. Moreover, the IVF/ICSI technique promotes higher rates of placental anomalies [46]. This observation corroborates the finding that impaired placentation at an inappropriate uterine site [25] might have a potential effect on the single loss in twins, particularly following IVF/ICSI. A recent case report suggested an association between VT pregnancies, especially after ART, and umbilical cord insertion anomalies, such as vasa previa. The common pathway may be the inadequate orientation of the blastocyst at the time of implantation after the ART procedure and the abnormal placental development, remodeling or suboptimal myometrial perfusion, which is characteristic of VT pregnancies [58].

Our most striking result is that the resorption of an embryo induces a growth restriction in the remaining twin, particularly after IVF/ICSI, compared to age- and previous gestationmatched singletons. This observation is a consistent finding in other reports [27]-[29], [48], [59], [60].

It is indeed a remarkable fact that IVF/ICSI has been associated independently with an increased risk of IUGR [61], with the risk being more pronounced in IVF/ICSI VT pregnancies [10], [11], [26], [28], [29], [34], [35]. In Paper 1, elevated odds of IUGR greater than nine times and fourfold odds for LBW were observed for VT after IVF/ICSI, whereas the respective figures for natural conception were only 3.0 and 2.1. One reason for this difference may be that the VT phenomenon in IVF/ICSI pregnancies was detected at a greater gestational length, suggesting that reduction occurs at a later stage. Later timing for the demise of a co-twin in IVF/ICSI might indicate that it is not the quality of the vanished embryo that is the dominant factor, but the uterine environment [11], [42] or the impaired utero-fetal interaction of the developing co-twin with possibly normal growth potential [31]. One can speculate that the larger fetoplacental tissue requires a longer elimination process [62], resulting in a poorer obstetric outcome [28], [29]. During restoration, the remodeling of the fetoplacental blood flow might be driven by 
decomposition products from the vanishing fetus. Hence, blood flow towards the surviving twin might be decreased temporarily, inducing a relative placental insufficiency, which could delay placental expansion and retard fetal growth. Interestingly, we did not find that the vanishing fetus had any significant influence on the rate of preterm birth either in the IVF/ICSI group or in the spontaneous group, a result which contrasts with other epidemiological and observational studies [28], [34], but confirms still other studies [22], [27], [63]. In relation to low birth weight and preterm birth, the perinatal outcome of VT after ART has been found similar to singletons and better than twin pregnancies in other retrospective studies [63], [64].

One intriguing finding was that we did not find any very preterm births in our VT groups. Our study provides evidence that adverse outcomes of VT pregnancies are more likely to be associated with the greater odds of lower birth weight and an increased proportion of agerelated morbidities, which are usually more common in IVF pregnancies [46], [65]-[67]. The rate of congenital malformation was slightly higher in vanishing pregnancies after assisted reproduction, but like other studies, it does not cause an increase in the risk of adverse outcomes [65], [68].

\section{CONCLUSION}

In conclusion, a more adverse pregnancy and neonatal outcome seem to be present in VT pregnancies following IVF/ICSI, thus confirming the concept of underlying maternal factors related to infertility or ART. Our results did not show whether VT is generated by the technique, the infertility due to underlying impairment or other IVF-related factors (i.e. fresh or frozen cycles or other stimulation protocol details). It appears that different pathological processes might cause VT and eliminate the fetoplacental unit in a different uterine environment, thus exhibiting a trend toward higher rates of perinatal complications in IVF/ICSI pregnancies compared to those conceived spontaneously. Spontaneous reduction occurs more frequently in spontaneous twin pregnancies than in conceptions after assisted reproduction. The main findings of the high rate of IUGR neonates in connection with certain maternal illnesses are related to adverse perinatal outcome in VT pregnancies.

Conversely, VT is more likely to occur after spontaneous implantation of two embryos $(2.9 \%)$ than after the iatrogenic transfer of two embryos $(0.35 \%)$. Both pregestational and gestational diabetes and placentation/placental anomalies are associated with the VT 
phenomenon. To our knowledge, no study has yielded spontaneously conceived VT pregnancy outcomes with relatively high case numbers and compared with VT pregnancies after ART until now.

Recognizing vanishing twin by mode of conception and treating VT pregnancies as a possible high risk for intrauterine growth restriction, placental abnormalities and gestational diabetes hold the key for more effective prenatal care for that significant subgroup of pregnancies.

In the future, we would like to continue our research, extend analysis of data from VT pregnancies after ART with special interest in culture medium, mode of ART, and improvement and effect of embryo cryopreservation or embryo transfer policy on VT pregnancy outcome. For further consistency, prospective epidemiological studies of neonatal outcome are necessary to investigate the role of less prevalent miscarriage-related factors. 


\section{SUMMARY OF NEW FINDINGS}

- The incidence of VT pregnancies after natural implantation is $18.2 \%$, which is higher than among VT pregnancies after assisted reproductive techniques (12.6\%).

- The average gestational length at the time of vanishing in the IVF/ICSI group was $9.86 \pm 2.06$ weeks and $8.86 \pm 2.70$ weeks in the spontaneous group.

- A higher rate and increased incidence of pre-gestational and gestational diabetes mellitus, abnormal placentation and placental anomalies are associated with the VT phenomenon. VT was still noted as an independent risk factor for adverse perinatal outcome after controlling for all possible confounders.

- VTS poses a higher risk for an adverse perinatal outcome following IVF/ICSI as compared with spontaneously conceived counterparts.

- The IVF/ICSI technology and the underlying pathomechanisms which finally lead to infertility worsen the poorer outcome of vanishing twin pregnancies.

- VTS induces growth restriction in the remaining twin.

- Chronic maternal diseases and an anamnestic history of GDM or IUGR can contribute to the absorption of a single embryo in twin pregnancy, particularly in IVF/ICSI pregnancies.

- An adverse obstetric history comprising induced abortion and second-trimester fetal loss as risk factors is strongly associated with vanishing twins in spontaneous pregnancies. 


\section{ACKNOWLEDGEMENTS}

The present project has been carried out at the Department of Obstetrics and Gynecology, University of Szeged.

Firstly, I am grateful to Attila Keresztúri, who generously agreed to be my supervisor. $\mathrm{He}$ has given me constructive criticism, supporting me in all the parts of this project and provided me with this research topic.

I wish to express my deepest gratitude to my co-author, Zoltán Kozinszky. His endless enthusiasm and interesting research ideas finally convinced me that statistics and epidemiology provided important answers. I have gained great respect for his professional skills. During all parts of this project, he has patiently guided me through statistical methods and solutions without giving up on me. Thanks for the discussions, comfort and friendship.

I am very thankful to Professor Gábor Németh, the Head of the Department of Obstetrics and Gynecology, for his kind support throughout my studies. I thank him for giving me the opportunity to work on my thesis.

I wish to express my sincere gratitude to Professor György Bártfai MD., DSc., for his support.

I would also like to say a big thank you to Thomas Williams, who successfully prepared me for my English exams and generously assumed the linguistic revision of my scientific papers and thesis.

I would also like to thank my colleagues, especially my dear colleague, János Zádori, for his support for and interest in my work. 


\section{REFERENCES}

[1] J. G. Hall, “Twinning," Lancet, vol. 362, no. 9385, pp. 735-743, 0 2003, doi: 10.1016/S0140-6736(03)14237-7.

[2] D. Caserta et al., "Maternal and perinatal outcomes in spontaneous versus assisted conception twin pregnancies," Eur. J. Obstet. Gynecol. Reprod. Biol., vol. 174, pp. 64-69, Mar. 2014, doi: 10.1016/j.ejogrb.2013.12.011.

[3] R. Bortolus, F. Parazzini, L. Chatenoud, G. Benzi, M. M. Bianchi, and A. Marini, "The epidemiology of multiple births," Hum. Reprod. Update, vol. 5, no. 2, pp. 179-187, Apr. 1999, doi: 10.1093/humupd/5.2.179.

[4] C. Hoekstra et al., "Dizygotic twinning," Hum. Reprod. Update, vol. 14, no. 1, pp. 3747, Feb. 2008, doi: 10.1093/humupd/dmm036.

[5] B. C. J. M. Fauser, P. Devroey, and N. S. Macklon, "Multiple birth resulting from ovarian stimulation for subfertility treatment," Lancet, vol. 365, no. 9473, pp. 1807-1816, May 2005, doi: 10.1016/S0140-6736(05)66478-1.

[6] C. De Geyter et al., "ART in Europe, 2014: results generated from European registries by ESHRE: The European IVF-monitoring Consortium (EIM) for the European Society of Human Reproduction and Embryology (ESHRE)," Hum. Reprod., vol. 33, no. 9, pp. 15861601, 01 2018, doi: 10.1093/humrep/dey242.

[7] S. Tong, D. Caddy, and R. V. Short, "Use of dizygotic to monozygotic twinning ratio as a measure of fertility," Lancet, vol. 349, no. 9055, pp. 843-845, Mar. 1997, doi: 10.1016/S0140-6736(96)10003-9.

[8] H. J. Landy and L. G. Keith, "The vanishing twin: a review," Hum. Reprod. Update, vol. 4, no. 2, pp. 177-183, Apr. 1998, doi: 10.1093/humupd/4.2.177.

[9] O. A. Oloyede, F. Iketubosin, and K. Bamgbopa, "Spontaneous fetal reduction and early pregnancy complications in multiple pregnancies following in vitro fertilization," Int $J$ Gynaecol Obstet, vol. 119, no. 1, pp. 57-60, Oct. 2012, doi: 10.1016/j.ijgo.2012.05.021.

[10] P. Tummers, P. De Sutter, and M. Dhont, "Risk of spontaneous abortion in singleton and twin pregnancies after IVF/ICSI," Hum. Reprod., vol. 18, no. 8, pp. 1720-1723, 0 2003, doi: 10.1093/humrep/deg308. 
[11] R. P. Dickey et al., "Spontaneous reduction of multiple pregnancy: incidence and effect on outcome," Am. J. Obstet. Gynecol., vol. 186, no. 1, pp. 77-83, 0 2002, doi: 10.1067/mob.2002.118915.

[12] A. Sampson and L. C. de Crespigny, "Vanishing twins: the frequency of spontaneous fetal reduction of a twin pregnancy," Ultrasound Obstet Gynecol, vol. 2, no. 2, pp. 107-109, Mar. 1992, doi: 10.1046/j.1469-0705.1992.02020107.x.

[13] M. R. Wax, M. Frates, C. B. Benson, J. Yeh, and P. M. Doubilet, "First trimester findings in pregnancies after in vitro fertilization," J Ultrasound Med, vol. 11, no. 7, pp. 321325, Jul. 1992, doi: 10.7863/jum.1992.11.7.321.

[14] R. P. Dickey, T. T. Olar, D. N. Curole, S. N. Taylor, P. H. Rye, and E. M. Matulich, "The probability of multiple births when multiple gestational sacs or viable embryos are diagnosed at first trimester ultrasound," Hum. Reprod., vol. 5, no. 7, pp. 880-882, Oct. 1990, doi: 10.1093/oxfordjournals.humrep.a137202.

[15] Y. Ezra and J. G. Schenker, "Abortion rate in assisted reproduction--true increase?," Early Pregnancy, vol. 1, no. 3, pp. 171-175, Sep. 1995.

[16] C. Simón, J. Landeras, J. L. Zuzuarregui, J. C. Martín, J. Remohí, and A. Pellicer, “Early pregnancy losses in in vitro fertilization and oocyte donation," Fertil. Steril., vol. 72, no. 6, pp. 1061-1065, 0 1999, doi: 10.1016/s0015-0282(99)00408-2.

[17] F. D'Antonio, A. Khalil, T. Dias, B. Thilaganathan, and Southwest Thames Obstetric Research Collaborative (STORK), "Early fetal loss in monochorionic and dichorionic twin pregnancies: analysis of the Southwest Thames Obstetric Research Collaborative (STORK) multiple pregnancy cohort," Ultrasound Obstet Gynecol, vol. 41, no. 6, pp. 632-636, Jun. 2013, doi: $10.1002 /$ uog. 12363.

[18] S. G. M. Carroll, L. Tyfield, L. Reeve, H. Porter, P. Soothill, and P. M. Kyle, "Is zygosity or chorionicity the main determinant of fetal outcome in twin pregnancies?, Am. J. Obstet. Gynecol., vol. 193, no. 3 Pt 1, pp. 757-761, Sep. 2005, doi: 10.1016/j.ajog.2005.01.024.

[19] S. Levi, "Ultrasonic assessment of the high rate of human multiple pregnancy in the first trimester," J Clin Ultrasound, vol. 4, no. 1, pp. 3-5, Feb. 1976, doi: 10.1002/jcu.1870040104.

[20] E. Jauniaux, N. Elkazen, F. Leroy, P. Wilkin, F. Rodesch, and J. Hustin, "Clinical and morphologic aspects of the vanishing twin phenomenon," Obstet Gynecol, vol. 72, no. 4, pp. 
577-581, Oct. 1988.

[21] H. J. Landy, S. Weiner, S. L. Corson, F. R. Batzer, and R. J. Bolognese, "The 'vanishing twin': ultrasonographic assessment of fetal disappearance in the first trimester," Am. J. Obstet. Gynecol., vol. 155, no. 1, pp. 14-19, Jul. 1986, doi: 10.1016/0002-9378(86)90068-2.

[22] S. E. Barton, S. A. Missmer, and M. D. Hornstein, "Twin pregnancies with a 'vanished' embryo: a higher risk multiple gestation group?," Hum. Reprod., vol. 26, no. 10, pp. 2750 2753, Oct. 2011, doi: 10.1093/humrep/der221.

[23] N. Greenwold and E. Jauniaux, "Collection of villous tissue under ultrasound guidance to improve the cytogenetic study of early pregnancy failure," Hum. Reprod., vol. 17, no. 2, pp. 452-456, Feb. 2002, doi: 10.1093/humrep/17.2.452.

[24] E. Jauniaux, R. H. F. Van Oppenraaij, and G. J. Burton, “Obstetric outcome after early placental complications," Curr. Opin. Obstet. Gynecol., vol. 22, no. 6, pp. 452-457, 0 2010, doi: 10.1097/GCO.0b013e3283404e44.

[25] R. Depp, G. A. Macones, M. F. Rosenn, E. Turzo, R. J. Wapner, and V. J. Weinblatt, "Multifetal pregnancy reduction: evaluation of fetal growth in the remaining twins," Am. J. Obstet. Gynecol., vol. 174, no. 4, pp. 1233-1238; discussion 1238-1240, Apr. 1996, doi: 10.1016/s0002-9378(96)70666-x.

[26] B. Almog et al., "Adverse obstetric outcome for the vanishing twin syndrome," Reprod. Biomed. Online, vol. 20, no. 2, pp. 256-260, Feb. 2010, doi: 10.1016/j.rbmo.2009.11.015.

[27] O. Shebl, T. Ebner, M. Sommergruber, A. Sir, and G. Tews, "Birth weight is lower for survivors of the vanishing twin syndrome: a case-control study," Fertil. Steril., vol. 90, no. 2, pp. 310-314, 0 2008, doi: 10.1016/j.fertnstert.2007.06.048.

[28] A. Pinborg, O. Lidegaard, N. la Cour Freiesleben, and A. N. Andersen, "Consequences of vanishing twins in IVF/ICSI pregnancies," Hum. Reprod., vol. 20, no. 10, pp. 2821-2829, Oct. 2005, doi: 10.1093/humrep/dei142.

[29] A. Pinborg, O. Lidegaard, N. la C. Freiesleben, and A. N. Andersen, "Vanishing twins: a predictor of small-for-gestational age in IVF singletons," Hum. Reprod., vol. 22, no. 10, pp. 2707-2714, Oct. 2007, doi: 10.1093/humrep/dem225.

[30] O. Ishihara et al., "International committee for monitoring assisted reproductive technologies: world report on assisted reproductive technologies, 2007," Fertil. Steril., vol. 103, 
no. 2, pp. 402-413.e11, Feb. 2015, doi: 10.1016/j.fertnstert.2014.11.004.

[31] G. B. La Sala, A. Nicoli, M. T. Villani, A. Gallinelli, G. Nucera, and I. Blickstein, "Spontaneous embryonic loss rates in twin and singleton pregnancies after transfer of topversus intermediate-quality embryos," Fertil. Steril., vol. 84, no. 6, pp. 1602-1605, 0 2005, doi: 10.1016/j.fertnstert.2005.05.045.

[32] E. Jauniaux, I. Ben-Ami, and R. Maymon, "Do assisted-reproduction twin pregnancies require additional antenatal care?," Reprod. Biomed. Online, vol. 26, no. 2, pp. 107-119, Feb. 2013, doi: 10.1016/j.rbmo.2012.11.008.

[33] H. J. Landy, L. Keith, and D. Keith, "The vanishing twin," Acta Genet Med Gemellol (Roma), vol. 31, no. 3-4, pp. 179-194, 1982, doi: 10.1017/s0001566000008278.

[34] S. T. Chasen, G. Luo, S. C. Perni, and R. B. Kalish, "Are in vitro fertilization pregnancies with early spontaneous reduction high risk?," Am. J. Obstet. Gynecol., vol. 195, no. 3, pp. 814-817, Sep. 2006, doi: 10.1016/j.ajog.2006.06.022.

[35] E. Evron, E. Sheiner, M. Friger, R. Sergienko, and A. Harlev, "Vanishing twin syndrome: is it associated with adverse perinatal outcome?," Fertil. Steril., vol. 103, no. 5, pp. 1209-1214, May 2015, doi: 10.1016/j.fertnstert.2015.02.009.

[36] S. T. Chasen, S. C. Perni, M. Predanic, R. B. Kalish, and F. A. Chervenak, "Does a 'vanishing twin' affect first-trimester biochemistry in Down syndrome risk assessment?," Am. J. Obstet. Gynecol., vol. 195, no. 1, pp. 236-239, Jul. 2006, doi: 10.1016/j.ajog.2006.01.044.

[37] K. Spencer, I. Staboulidou, and K. H. Nicolaides, "First trimester aneuploidy screening in the presence of a vanishing twin: implications for maternal serum markers," Prenat. Diagn., vol. 30, no. 3, pp. 235-240, Mar. 2010, doi: 10.1002/pd.2445.

[38] F. F. Thurik et al., "Analysis of false-positive results of fetal RHD typing in a national screening program reveals vanishing twins as potential cause for discrepancy," Prenat. Diagn., vol. 35 , no. 8 , pp. $754-760,0$ 2015, doi: 10.1002/pd.4600.

[39] K. J. Curnow et al., "Detection of triploid, molar, and vanishing twin pregnancies by a single-nucleotide polymorphism-based noninvasive prenatal test," Am. J. Obstet. Gynecol., vol. 212, no. 1, pp. 79.e1-9, 0 2015, doi: 10.1016/j.ajog.2014.10.012.

[40] T. Futch, J. Spinosa, S. Bhatt, E. de Feo, R. P. Rava, and A. J. Sehnert, "Initial clinical laboratory experience in noninvasive prenatal testing for fetal aneuploidy from maternal plasma 
DNA samples," Prenat. Diagn., vol. 33, no. 6, pp. 569-574, Jun. 2013, doi: 10.1002/pd.4123.

[41] H. Martikainen et al., "One versus two embryo transfer after IVF and ICSI: a randomized study," Hum. Reprod., vol. 16, no. 9, pp. 1900-1903, Sep. 2001, doi: 10.1093/humrep/16.9.1900.

[42] G. B. La Sala, M. T. Villani, A. Nicoli, A. Gallinelli, G. Nucera, and I. Blickstein, "Effect of the mode of assisted reproductive technology conception on obstetric outcomes for survivors of the vanishing twin syndrome," Fertil. Steril., vol. 86, no. 1, pp. 247-249, Jul. 2006, doi: 10.1016/j.fertnstert.2005.11.073.

[43] Y. A. Wang, E. A. Sullivan, D. Black, J. Dean, J. Bryant, and M. Chapman, "Preterm birth and low birth weight after assisted reproductive technology-related pregnancy in Australia between 1996 and 2000," Fertil. Steril., vol. 83, no. 6, pp. 1650-1658, Jun. 2005, doi: 10.1016/j.fertnstert.2004.12.033.

[44] J. S. Younis, "Ovarian aging: latest thoughts on assessment and management," Curr. Opin. Obstet. Gynecol., vol. 23, no. 6, pp. 427-434, 0 2011, doi: 10.1097/GCO.0b013e32834b92b0.

[45] M. Roque et al., "Fresh embryo transfer versus frozen embryo transfer in in vitro fertilization cycles: a systematic review and meta-analysis," Fertil. Steril., vol. 99, no. 1, pp. 156-162, 0 2013, doi: 10.1016/j.fertnstert.2012.09.003.

[46] A. Pinborg et al., "Why do singletons conceived after assisted reproduction technology have adverse perinatal outcome? Systematic review and meta-analysis," Hum. Reprod. Update, vol. 19, no. 2, pp. 87-104, Apr. 2013, doi: 10.1093/humupd/dms044.

[47] H. W. Jones, "Multiple births: how are we doing?," Fertil. Steril., vol. 79, no. 1, pp. 1721, 0 2003, doi: 10.1016/s0015-0282(02)04565-x.

[48] L. A. Schieve, S. F. Meikle, C. Ferre, H. B. Peterson, G. Jeng, and L. S. Wilcox, "Low and very low birth weight in infants conceived with use of assisted reproductive technology," N. Engl. J. Med., vol. 346, no. 10, pp. 731-737, Mar. 2002, doi: 10.1056/NEJMoa010806.

[49] E. Jauniaux, R. G. Farquharson, O. B. Christiansen, and N. Exalto, "Evidence-based guidelines for the investigation and medical treatment of recurrent miscarriage," Hum. Reprod., vol. 21, no. 9, pp. 2216-2222, Sep. 2006, doi: 10.1093/humrep/del150.

[50] A. Maheshwari, S. Pandey, A. Shetty, M. Hamilton, and S. Bhattacharya, "Obstetric and 
perinatal outcomes in singleton pregnancies resulting from the transfer of frozen thawed versus fresh embryos generated through in vitro fertilization treatment: a systematic review and metaanalysis," Fertil. Steril., vol. 98, no. 2, pp. 368-377.e1-9, 0 2012, doi: 10.1016/j.fertnstert.2012.05.019.

[51] E. A. Rhon-Calderon, L. A. Vrooman, L. Riesche, and M. S. Bartolomei, "The effects of Assisted Reproductive Technologies on genomic imprinting in the placenta," Placenta, vol. 84, pp. 37-43, 01 2019, doi: 10.1016/j.placenta.2019.02.013.

[52] H. Lou et al., "Aberrant DNA Methylation of IGF2-H19 Locus in Human Fetus and in Spermatozoa From Assisted Reproductive Technologies," Reprod Sci, vol. 26, no. 7, pp. 9971004, 2019, doi: 10.1177/1933719118802052.

[53] M. Ashrafi, R. Gosili, R. Hosseini, A. Arabipoor, J. Ahmadi, and M. Chehrazi, "Risk of gestational diabetes mellitus in patients undergoing assisted reproductive techniques," Eur. $J$. Obstet. Gynecol. Reprod. Biol., vol. 176, pp. 149-152, May 2014, doi: 10.1016/j.ejogrb.2014.02.009.

[54] I. Blickstein, S. Mincha, R. D Goldman, G. A Machin, and L. G Keith, "The Northwestern twin chorionicity study: testing the "placental crowding' hypothesis," J Perinat Med, vol. 34, no. 2, pp. 158-161, 2006, doi: 10.1515/JPM.2006.028.

[55] O. P. Bleker, J. Oosting, and D. J. Hemrika, "On the cause of the retardation of fetal growth in multiple gestations," Acta Genet Med Gemellol (Roma), vol. 37, no. 1, pp. 41-46, 1988, doi: 10.1017/s0001566000004244.

[56] G. Rizzo, A. Capponi, M. E. Pietrolucci, E. Aiello, and D. Arduini, "First trimester placental volume and three dimensional power doppler ultrasonography in type I diabetic pregnancies," Prenat. Diagn., vol. 32, no. 5, pp. 480-484, May 2012, doi: 10.1002/pd.3848.

[57] M. R. Loeken, "Advances in understanding the molecular causes of diabetes-induced birth defects," J. Soc. Gynecol. Investig., vol. 13, no. 1, pp. 2-10, 0 2006, doi: 10.1016/j.jsgi.2005.09.007.

[58] Y. Melcer et al., "Is scanning for vasa previa important for singleton pregnancies that started as multiple conceptions?," Eur. J. Obstet. Gynecol. Reprod. Biol., vol. 238, pp. 100103, Jul. 2019, doi: 10.1016/j.ejogrb.2019.05.018.

[59] B. Luke et al., "The effect of early fetal losses on singleton assisted-conception 
pregnancy outcomes," Fertil. Steril., vol. 91, no. 6, pp. 2578-2585, Jun. 2009, doi: 10.1016/j.fertnstert.2008.03.068.

[60] A. Sazonova, K. Källen, A. Thurin-Kjellberg, U.-B. Wennerholm, and C. Bergh, "Factors affecting obstetric outcome of singletons born after IVF," Hum. Reprod., vol. 26, no. 10, pp. 2878-2886, Oct. 2011, doi: 10.1093/humrep/der241.

[61] A. L. Wennberg et al., "Effect of maternal age on maternal and neonatal outcomes after assisted reproductive technology," Fertil. Steril., vol. 106, no. 5, pp. 1142-1149.e14, Oct. 2016, doi: 10.1016/j.fertnstert.2016.06.021.

[62] H. N. Bass, J. B. Oliver, M. Srinivasan, R. Petrucha, W. Ng, and J. E. Lee, "Persistently elevated AFP and AChE in amniotic fluid from a normal fetus following demise of its twin," Prenat. Diagn., vol. 6, no. 1, pp. 33-35, Feb. 1986, doi: 10.1002/pd.1970060105.

[63] P. A. Romanski et al., "Perinatal and Peripartum Outcomes in Vanishing Twin Pregnancies Achieved by In Vitro Fertilization," Obstet Gynecol, vol. 131, no. 6, pp. $1011-$ 1020, 2018, doi: 10.1097/AOG.0000000000002595.

[64] T. Joseph, H. Y. Selliah, M. Karthikeyan, A. Chandy, A. T. Kunjummen, and M. S. Kamath, "Comparison of Perinatal Outcomes of Singletons Following Vanishing Twin Phenomenon and Singletons with Initial Single Gestational Sac Conceived Following Assisted Reproductive Technology: A Retrospective Analysis," J Hum Reprod Sci, vol. 12, no. 2, pp. 164-168, Jun. 2019, doi: 10.4103/jhrs.JHRS_127_18.

[65] J. Yan et al., "Neonatal outcomes of singleton live births with vanishing twin syndrome following double embryos transfer in assisted reproductive technology: a retrospective cohort study," J Ovarian Res, vol. 12, no. 1, p. 67, Jul. 2019, doi: 10.1186/s13048-019-0539-8.

[66] M. S. Kamath, B. Antonisamy, H. Y. Selliah, and S. K. Sunkara, "Perinatal outcomes of singleton live births with and without vanishing twin following transfer of multiple embryos: analysis of 113784 singleton live births," Hum. Reprod., vol. 33, no. 11, pp. 2018-2022, 01 2018, doi: 10.1093/humrep/dey284.

[67] M. C. Magnus et al., "Vanishing twin syndrome among ART singletons and pregnancy outcomes," Hum. Reprod., vol. 32, no. 11, pp. 2298-2304, 01 2017, doi: 10.1093/humrep/dex277.

[68] P. O. D. Pharoah, S. V. Glinianaia, and J. Rankin, "Congenital anomalies in multiple 
births after early loss of a conceptus," Hum. Reprod., vol. 24, no. 3, pp. 726-731, Mar. 2009, doi: 10.1093/humrep/den436. 